\title{
Viroides em citros
}

\author{
Marcelo Eiras ${ }^{1}$, Simone Rodrigues Silva ${ }^{2}$, Eduardo Sanches Stuchi ${ }^{3,4}$, Maria Luisa Penteado Natividade \\ Targon $^{5}$ \& Sérgio Alves Carvalho 5
}

${ }^{1}$ Laboratório de Fitovirologia e Fisiopatologia, Centro de Pesquisa e Desenvolvimento de Sanidade Vegetal, Instituto Biológico, 04014-002, São Paulo, SP, Brasil; ${ }^{2}$ Departamento de Produção Vegetal, ESALQ, Universidade de São Paulo, 13418-970, Piracicaba, SP, Brasil; ${ }^{3}$ Estação Experimental de Citricultura de Bebedouro, Embrapa, 14700-971, Bebedouro, SP, Brasil; ${ }^{4}$ Embrapa Mandioca e Fruticultura Tropical, 44380 000, Cruz das Almas, BA, Brasil; ${ }^{5}$ Centro de Citricultura Sylvio Moreira, Instituto Agronômico da Campinas IAC, 13490-970, Cordeirópolis, SP, Brasil

Autor para correspondência: Marcelo Eiras, e-mail: eiras@biologico.sp.gov.br

\section{RESUMO}

Os viroides são os menores fitopatógenos conhecidos. Constituídos por uma molécula de RNA de fita simples, circular, que não é encapsidada e não codifica proteínas, são capazes de se replicar de maneira autônoma nas células do hospedeiro. Os viroides de citros pertencem à família Pospiviroidae (cujos membros apresentam uma região central conservada, replicam-se no núcleo das células hospedeiras e não apresentam atividade ribozimática) com cinco espécies: Citrus exocortis viroid, CEVd (Pospiviroid), Hop stunt viroid, HSVd (Hostuviroid), Citrus bark cracking viroid, CBCVd (Cocadviroid) e Citrus bent leaf viroid, CBLVd e Citrus dwarfing viroid, CDVd (Apscaviroid). Além disso, Citrus viroid original source (CVd-OS) e mais recentemente, Citrus viroid V (CVd-V) foram propostas como espécies tentativas do gênero Apscaviroid. Os viroides de citros são transmitidos via enxertia e disseminados principalmente pela propagação de material contaminado. Sabe-se que os viroides de citros infectam praticamente todas as espécies do gênero Citrus e afins. Porém, há somente duas doenças importantes descritas em citros, induzidas por viroides: (i) a exocorte; (ii) e a xiloporose (ou cachexia). Apesar dos viroides induzirem sintomas severos, ou simplesmente afetarem o tamanho das árvores, muitas espécies de citros são assintomáticas, sendo o controle baseado em medidas preventivas, como utilização de gemas livres de viroides aliadas a métodos confiáveis de indexação. A proposta desta revisão é apresentar ao leitor os recentes avanços nas pesquisas com viroides de citros, principalmente na taxonomia, distribuição geográfica, métodos de detecção, limpeza e indexação, epidemiologia e controle, além do histórico e importância desses patógenos para a citricultura mundial.

Palavras-chave: Citrus exocortis, Hop stunt, Pospiviroid, Apscaviroid, Cocadviroid, Hostuviroid, Exocorte, Xiloporose.

\section{ABSTRACT \\ Viroids in Citrus}

Viroids are the smallest known plant pathogens consisting of a non-encapsidated, circular, single-stranded RNA that replicate autonomously in their host plants. Viroids are classified into two families (Pospiviroidae and Avsunviroidae). All citrus viroids belong to the Pospiviroidae family (species that present a central conserved region, replicate in the nucleus of infected cells and lack of ribozyme activity) with five citrus viroid species: Citrus exocortis viroid, CEVd (Pospiviroid), Hop stunt viroid, HSVd (Hostuviroid), Citrus bark cracking viroid, CBCVd (Cocadviroid) and Citrus bent leaf viroid, CBLVd and Citrus dwarfing viroid, CDVd (Apscaviroid). In addition, Citrus viroid original source (CVd-OS) and, more recently, Citrus viroid V (CVd-V) have been proposed as tentative species of the genus Apscaviroid. Citrus viroids are graft-transmitted and their dissemination occurs mainly by propagation of contaminated material. It is known that they have a broad host range, infecting species of citrus and plants of citrus-related genera. Two important diseases in citrus are viroid-induced: (i) exocortis; (ii) and cachexia. Symptoms vary from severe to asymptomatic, and their control is based on preventive measures as availability of viroid-free budwood as a source of propagation material follow by adequate indexing procedures. The purpose of this review is to present the reader the recent advances on citrus viroid research, mainly on taxonomy, geographical distribution, methods of detection, indexing and cleaning, epidemiology and control.

Keywords: Hop stunt, Citrus exocortis, Pospiviroid, Apscaviroid, Cocadviroid, Hostuviroid, Exocortis, Xyloporosis.

\section{INTRODUÇÃO}

A descoberta dos viroides, minúsculas moléculas de RNA de fita simples, circulares, que não codificam proteínas, porém capazes de replicação autônoma e de induzir doenças de importância econômica em plantas superiores, abriu as portas para mais um novo universo de conhecimento ainda limitado da biologia: o estudo dos pequenos RNA não traduzíveis (non-coding RNA). O estudo dos viroides nasce com a elucidação, no início da década de 1970, dos agentes etiológicos de duas doenças de importância econômica, inicialmente atribuídas a vírus: o "afilamento do tubérculo da batatinha" (Solanum tuberosum) e a "exocorte dos citros" (Citrus spp.), causadas, respectivamente, pelo Potato 
spindle tuber viroid (PSTVd) e Citrus exocortis viroid (CEVd) (Diener, 1971; Semancik \& Weathers, 1972a). Da mesma forma como ocorreu com essas duas doenças, para outras enfermidades, inicialmente consideradas de etiologia viral, comprovou-se posteriormente que o agente causal era um viroide e não vírus. Sendo assim, outros viroides foram identificados e caracterizados em diversas espécies de plantas (Singh et al., 2003).

Os viroides são agentes subvirais, com tamanho que pode variar de 246 a 401 nucleotídeos, cerca de dez vezes menores do que os menores genomas virais conhecidos. Considerados parasitas da maquinaria transcricional do núcleo ou cloroplasto (ao contrário dos vírus de plantas de RNA que se replicam no citoplasma, podendo ser considerados parasitas dos mecanismos de tradução celular), esses patógenos, exclusivos de plantas superiores, por não codificarem proteínas próprias, são totalmente dependentes da célula hospedeira para completar as etapas de seu ciclo infeccioso que inclui replicação, movimento e patogênese [ver, para uma revisão Eiras et al. (2006); Flores \& Owens (2008); Tsagris et al. (2008); Ding (2009); Ding \& Wang (2009)].

A taxonomia moderna agrupa os viroides em Famílias, Gêneros, Espécies e Variantes. De acordo com suas propriedades biológicas e moleculares, os viroides são atualmente classificados em duas famílias: Pospiviroidae [espécies que se replicam no núcleo das células infectadas por meio de um mecanismo de círculo rolante assimétrico, apresentam uma região central conservada (CCR), estrutura secundária em forma de bastonete e ausência de ribozimas] e Avsunviroidae [espécies que se replicam nos cloroplastos seguindo um mecanismo de círculo rolante simétrico, apresentam ribozimas (RNA auto-catalíticos) e não possuem CCR]. Atualmente, cerca de 30 espécies de viroides, distribuídas em sete gêneros são aceitas pelo "Comitê Internacional de Taxonomia de Vírus" (ICTV) (Flores et al., 2005b). A diferenciação de espécies baseiase na identidade de sequência de nucleotídeos e tem-se estabelecido arbitrariamente que, quando esta for inferior a $90 \%$, sejam consideradas como espécies distintas e, quando superior, sejam consideradas como variantes de uma mesma espécie. Além disso, pelo menos uma propriedade biológica diferencial deve ser considerada, como círculo de hospedeiros, modo de transmissão e o fenômeno de proteção cruzada (Flores et al., 2005b).

Das sete espécies de viroides que infectam citros, até hoje conhecidas, todas pertencem à família Pospiviroidae. Os viroides induzem em citros diferentes tipos de sintomas e, na maioria das vezes, estão presentes em co-infecções. Provavelmente, o CEVd e o Hop stunt viroid (HSVd) sejam os viroides de citros mais importantes do ponto de vista econômico, principalmente por causarem doenças que levam a perdas significativas, o que é sempre uma preocupação em se tratando de uma cultura que movimenta bilhões de dólares e gera milhares de empregos diretos e indiretos em diversos países dos cinco continentes (Mattos
Junior et al., 2005). Porém, os outros viroides, mesmo em infecções latentes, devem ser levados em consideração, sendo que em diversos países produtores (África do Sul, Argentina, Austrália, Brasil, Chile, Cuba, Espanha, EUA, Itália e Marrocos) são investidos milhões de dólares em programas de limpeza e indexação de matrizes de citros para diminuir os riscos de disseminação desses patógenos (Gumpf \& Navarro, 2003).

A presente revisão tem como objetivos apresentar ao leitor os primeiros trabalhos realizados no início do século 20 com os viroides de citros, até os avanços recentes nas pesquisas com esses patógenos, principalmente na taxonomia, distribuição geográfica, métodos de detecção, indexação e limpeza, epidemiologia e controle, além da descoberta de novos viroides, recentemente identificados e caracterizados.

\section{HISTÓRICO}

As primeiras descrições de doenças causadas por viroides em citros foram feitas no início do século 20 . Naquela época, acreditava-se que devido aos sintomas e ao não isolamento de outros patógenos, os agentes etiológicos pudessem ser de origem viral, mesmo porque até então não se imaginava a existência de uma classe de patógenos subvirais.

A exocorte dos citros foi descrita pela primeira vez em 1948 na Califórnia como causadora de escamação na casca e diferentes graus de nanismo em Poncirus trifoliata Raf. enxertado com determinadas variedades cítricas (Fawcet \& Klotz, 1948). Quase simultaneamente, demonstrou-se que uma alteração similar, conhecida como "scally butt" na Austrália desde a década de 1930, era transmissível por enxertia (Benton et al., 1949). Hoje se sabe que essas duas enfermidades, além de uma terceira detectada nos EUA e Brasil, ao serem enxertadas em determinadas variedades de copa sobre limoeiro Cravo (Citrus limonia Osbeck), e que foi denominada "enfermidade do limão Cravo" (Moreira, 1955, 1959), são a mesma doença (Duran-Vila, 1989a). Somente no início da década de 1970, Semancik \& Wheathers (1972a) demonstraram que o agente causal da exocorte, até então atribuída a um possível vírus, na verdade era um viroide, denoninado Citrus exocortis viroid (CEVd). Mesmo sem o conhecimento do agente etiológico, já se especulava sobre a possível existência de "raças" do patógeno que causava a exocorte (Fraser \& Levitt, 1959; Calavan \& Wheathers, 1961; Rossetti, 1961; Salibe \& Moreira, 1965). Foram descritas diferenças no período de incubação, distintos graus de nanismo, diferenças na intensidade de escamas, rachaduras e caneluras na casca das plantas inoculadas (Duran-Vila, 1989a).

Em 1964, definiu-se o uso de cidra 'Etrog' (Citrus medica L.) como um indicador rápido para a exocorte, capaz de se detectar também as "raças" que não causavam sintomas típicos em P. trifoliata e limoeiro 'Cravo' (Olson, 1968). Porém, a caracterização do patógeno e a intensificação dos trabalhos biológicos se deram após a descoberta da indicadora herbácea Gynura aurantiaca (Blume) DC. como hospedeira 
experimental do CEVd (Weathers \& Greer Jr., 1972). Em Gynura, o CEVd se acumula em altas concentrações e induz epinastia, distorção foliar e nanismo. A variação na intensidade de sintomas observada em cidra foi durante anos atribuída à presença de variantes de CEVd. As observações iniciais da possível presença de outros viroides foram feitas por Schlemmer et al. (1985) por meio de eletroforese em géis de poliacrilamida (PAGE). Com o incremento da técnica e utilização de PAGE sequencial (sPAGE), outros RNAs circulares com mobilidade distinta de CEVd foram observados. Essas moléculas estavam associadas a sintomas mais brandos em cidra, sugerindo a presença de outros viroides, o que se confirmou anos mais tarde (Duran-Vila et al., 1988b).

Duran-Vila et al. (1986, 1988a, 1988b) descreveram um complexo de viroides em citros catalogados em cinco grupos, os quais foram identificados pela mobilidade eletroforética distinta, baixa porcentagem de identidade de sequência, transmissão independente e hospedeiros distintos (Semancik \& Duran-Vila, 1991). Os cinco grupos [CEVd; Citrus viroid I (CVd-I); Citrus viroid II (CVd-II); Citrus viroid III (CVd-III); Citrus viroid IV (CVd-IV)] e a classificação atual dos viroides de citros estão descritos na Tabela 1. Ver mais adiante a descrição detalhada das propriedades biológicas e moleculares dos diferentes viroides que ocorrem em citros.

Portanto, a maior parte dos isolados estudados resultou ser mesclas de viroides e não abrangia todas as combinações possíveis nos cinco grupos. Mesclas artificiais foram obtidas mostrando-se estáveis como as naturais. $\mathrm{O}$ conceito de variantes de exocorte foi definido por diferentes autores ao observarem diferenças na severidade dos sintomas e no período de incubação. Entretanto, havia imprecisão destes critérios. Duran-Vila (1989a) propôs a terminologia de fonte de exocorte para materiais de campo que fossem positivos em qualquer teste diagnóstico, considerando como isolados de exocorte uma fonte que tivesse sido caracterizada quanto ao sintoma em cidreira 'Etrog 861S-1' e ao número e tipo de viroides determinados por seu perfil eletroforético. O conceito de variante ficaria restrito aos viroides de sequência de bases conhecida, nos quais se poderiam detectar pequenas variações de nucleotídeos. Para o CEVd tem sido identificado um grande número de variantes de sequência com severidade distinta. Porém, a possibilidade de outros viroides interferirem na expressão de sintomas moderados ou suaves da doença não pode ser descartada (Gandía \& Duran-Vila, 2002).

Outra doença dos citros de etiologia não determinada (possivelmente viral) também era conhecida desde o início do século 20: a "xiloporose". Essa doença, que causa danos importantes em algumas combinações de copa/portaenxerto, foi descrita pela primeira vez em lima doce (Citrus limettioides Tan.) na Palestina (Reichert \& Perlberger, 1934) e posteriormente observada em tangelo 'Orlando' ( $C$. paradisi Macfad. $\times$ C. reticulata Blanco), sendo denominada de "cachexia" (Childs, 1950). Inicialmente, sugeriuse a nomenclatura de Citrus cachexia viroid (CCaVd) (Semancik et al., 1988) e posteriormente de Citrus viroid II (CVd-II) (Reanwarakorn \& Semancik, 1998, 1999a). Com a caracterização molecular identificou-se que CVd-II e Hop stunt viroid (HSVd) tratavam-se do mesmo patógeno (Sano et al., 1988), com alguns variantes capazes de induzir a xiloporose (Levy \& Hadidi, 1993; Semancik et al., 1988).

\section{TRANSMISSÃO, SINTOMAS E DANOS}

Os viroides não têm vetores e são raramente transmitidos por pólen e sementes. Porém, apresentam elevada estabilidade em extrato, sendo facilmente transmitidos mecanicamente e por instrumentos de poda contaminados. A via principal de difusão dos viroides, sobretudo aqueles que afetam plantas lenhosas de interesse econômico, tem sido o intercâmbio de material propagativo infectado. A prática da enxertia é a principal responsável pela disseminação mundial dos viroides (Hadidi et al., 2003).

Os viroides se replicam, acumulam-se e induzem, nos hospedeiros, seus sintomas muito mais eficientemente em temperaturas elevadas $\left(30 \mathrm{a} 33^{\circ} \mathrm{C}\right)$ e a intensidades altas de

TABELA 1 - Classificação atual dos viroides de citros em família (Pospiviroidae), gêneros e espécies, de acordo com o Comitê Internacional de Taxonomia de Vírus, ICTV (Flores et al., 2005b)

\begin{tabular}{|c|c|c|c|c|}
\hline Família & Gênero & Espécie & Acronímia & Grupos $^{1}$ \\
\hline \multirow{7}{*}{ Pospiviroidae } & Pospiviroid & Citrus exocortis viroid & CEVd & CEVd \\
\hline & Apscaviroid & Citrus bent leaf viroid & CBLVd & CVd-I \\
\hline & Hostuviroid & Hop stunt viroid & HSVd & CVd-II \\
\hline & Apscaviroid & Citrus dwarfing viroid $^{2}$ & CDVd & CVd-III \\
\hline & Cocadviroid & Citrus bark cracking viroid ${ }^{2}$ & CBCVd & CVd-IV \\
\hline & Apscaviroid & Citrus viroid original source ${ }^{3}$ & CVd-OS & - \\
\hline & Apscaviroid & Citrus viroid $\mathrm{V}^{4}$ & CVd-V & - \\
\hline
\end{tabular}

${ }^{1}$ Grupos inicialmente propostos por Duran-Vila et al. (1988b); ${ }^{2}$ Nomenclatura recentemente proposta (Vernière et al., 2004); Espécies tentativas: ${ }^{3}$ Ito et al. (2001); ${ }^{4}$ Serra et al. (2008a). 
luz. Os sintomas também são influenciados pela virulência do isolado, pelo estado nutricional da planta e cultivar (Duran-Vila et al., 1988a). Os viroides induzem nas folhas, malformações, epinastia, rugosidade e manchas cloróticas e necróticas; no caule, podem induzir descoloração, caneluras, exsudação de goma e necrose; nos frutos e órgãos de reserva, causam deformação, descoloração e necrose; na planta como um todo, podem induzir nanismo, amarelecimento, definhamento da copa e em alguns casos extremos, levar à morte. Porém, muitas vezes a infecção transcorre de forma latente, sem a indução de sintomas perceptíveis. A ausência de sintomas foi uma das causas da rápida disseminação desses patógenos. Os sintomas induzidos por cada espécie de viroide de citros serão comentados mais adiante.

Cada espécie de viroide induz sintomas específicos em cidra e a associação de determinados viroides com sintomas específicos em campo é difícil já que quase sempre se encontram como mesclas. Plantas de citros infectadas com um complexo de viroides podem exibir sintomas semelhantes à exocorte na ausência do CEVd (Ito et al., 2002). Os sintomas causados por viroides são amplos e, na maioria das vezes, indistinguíveis dos causados por vírus. Os hospedeiros herbáceos e ornamentais infectados frequentemente exibem sintomas foliares de clorose, amarelecimento, lesões necróticas no limbo, epinastia e alterações na forma, tamanho e fragilidade da folha. Geralmente a planta infectada apresenta entrenós curtos e como consequência são anãs. Em plantas lenhosas, o período que transcorre da infecção à manifestação de sintomas pode ser de vários anos. Os sintomas mais comuns são lesões na casca do tronco ou galhos (fendas, caneluras, escamas, descamamento, exsudações e impregnações de goma). Os frutos das plantas infectadas podem apresentar alterações na forma e tamanho, e na casca podem aparecer manchas, cancros e suberização (Flores \& Duran-Vila, 1996).

Em campo, a exocorte caracteriza-se pelo aparecimento de caneluras verticais, escamação e descamação da casca (Figura 1A), manchas amarelas nos brotos tenros e nanismo em $P$. trifoliata e híbridos do grupo citrange, algumas variedades de lima [C. aurantiifolia (Christm.) Swingle] e limão [C. limon (L.) Burm.], limão 'Cravo' (C. limonia Osbeck), toranja (C. grandis Osbeck) (Duran-Vila, 1989a), bem como na limeira ácida 'Tahiti' $(C$. latifolia Tanaka) (Salibe \& Moreira, 1965). Nas combinações afetadas por determinados variantes do CEVd, a copa pode apresentar definhamento, vegetação esparsa, alteração na coloração das folhas e redução de crescimento (Figura 1D). Certas variedades tendem a apresentar copas mais abertas
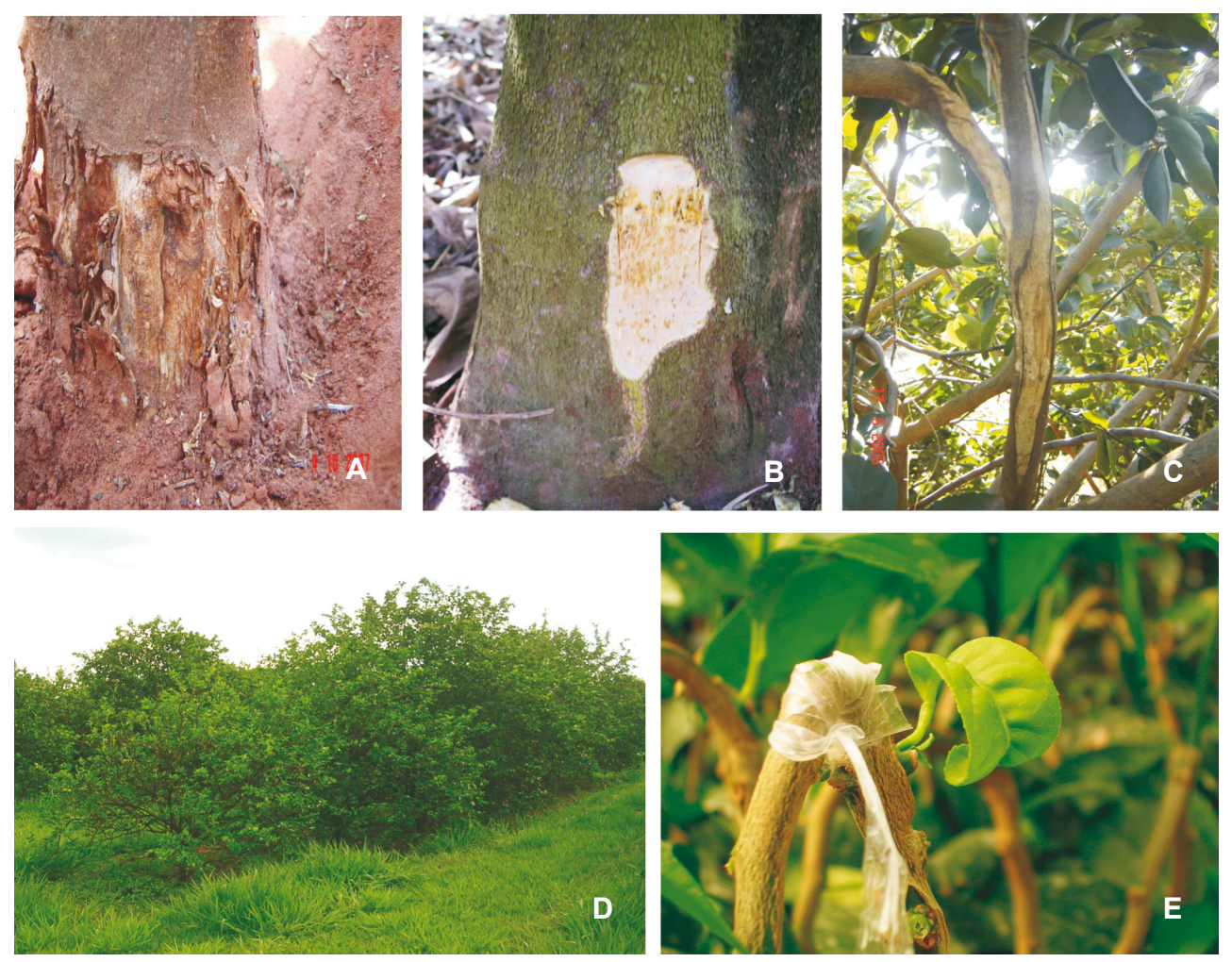

FIGURA 1 - Sintomas de viroides em citros: A. exocorte induzida pelo Citrus exocortis viroid (CEVd) em porta-enxerto de limoeiro 'Cravo'; B. Xiloporose induzida pelo Hop stunt viroid (HSVd); C. rachaduras (cracking) em ramos (copa) de limeira ácida 'Tahiti' induzidas pelo CEVd; D. nanismo em limeira ácida 'Tahiti' infectada por CEVd; E. Epinastia em cidreira infectada por uma mescla de CEVd, Citrus dwarfing viroid (CDVd) e Hop stunt viroid (HSVd) 
do que as das plantas sadias. Em porta-enxertos sensíveis de limoeiro 'Cravo', 'trifoliata' e alguns de seus híbridos, pode haver indução de um fendilhamento da parte externa da casca que se levanta, formando escamas de tamanho variável que, a princípio, ficam presas ao tronco da planta pela sua parte superior e que, num estado mais avançado da doença, caem, deixando abertas lesões de tamanho variável. Muitas vezes, antes do fendilhamento, nota-se a formação de goma na casca do porta-enxerto e os sintomas aparecem geralmente entre quatro e sete anos (Müller et al., 2005). Espécies tolerantes à exocorte induzem descamação em porta-enxertos sensíveis, mesmo quando a copa não é afetada. Variedades tolerantes enxertadas sobre um portaenxerto sensível serão árvores sensíveis ao CEVd (DuranVila, 2000). As perdas provocadas pela exocorte dependem da tolerância ou resistência do material cítrico plantado, podendo ocorrer desde poucos danos até redução na produção de frutos (Duran-Vila \& Semancik, 2003).

Quando a espécie sensível à xiloporose é a variedade enxertada, as plantas apresentam caneluras na madeira, que correspondem a elevações da casca e impregnação de goma (Figura 1B). A casca pode ficar grossa, inchada na região de união com o porta-enxerto e, em cortes transversais, podem se observar bolsas de goma. Quando o porta-enxerto é a espécie sensível, a copa apresenta um crescimento considerável na parte superior, devido à detenção do crescimento em diâmetro do porta-enxerto, enquanto a união copa/porta-enxerto das árvores sadias é lisa. Ao levantar a casca do porta-enxerto, observa-se a presença de fortes caneluras com impregnação de goma (Duran-Vila, 2000). Em condições de campo, o tempo de incubação necessário para a manifestação dos sintomas de xiloporose oscila entre 4 e 12 anos, dependendo do local de cultivo e da espécie infectada, parecendo existir uma relação entre a intensidade de sintomas e as condições climáticas da região de cultivo (Barbosa, 2004).

São desconhecidos os efeitos das infecções múltiplas do agente causal da xiloporose (HSVd) e outros viroides em espécies de citros consideradas sensíveis e tolerantes e suas implicações no desenvolvimento de sintomas e características agronômicas. Em tangerineira (C. reticulata Blanco) 'Parson's Special' têm-se demonstrado que a infecção simultânea com outros viroides pode inibir ou atrasar os sintomas (Pina et al., 1991). Para Vernière et al. (2006), a ocorrência de interações entre certas espécies de viroides, pode conduzir ao antagonismo ou sinergismo, podendo ter um efeito na expressão de sintomas e desempenho das árvores. Os autores constataram uma interação antagônica entre CEVd e CVd-IV, pois a presença do CVd-IV pode diminuir ou suprimir o efeito do CEVd no desenvolvimento e expressão de sintomas. Tratamentos com CBLVd, CVdIII e CVd-IV, na ausência de CEVd, sugeriram que o sinergismo entre esses três viroides foi responsável pelo sintoma de exocorte. O sinergismo também foi observado entre os viroides CVd-IV e HSVd, mas a presença de viroides adicionais limitaram este efeito. Ao contrário, o efeito sinérgico entre CEVd e CBLVd foi favorecido pela presença de viroides adicionais. A intensidade da expressão de sintomas, a redução do crescimento da copa e da produção são sempre mais evidentes em $P$. trifoliata que em limoeiro 'Cravo'. O vigor deste último foi sugerido como uma possível explicação para tal fato (Moreira, 1959). Há também nanismo pronunciado em árvores de $P$. trifoliata quando a exocorte soma-se à tristeza (Roistacher, 1991).

Os viroides CVd-I, CVd-IIa e CVd-III causam, respectivamente, depressões em forma de pontos no lenho, escamação na casca e um tipo de impressão de dedos em P. trifoliata. Para Vidalakis et al. (2004), o aparecimento do sintoma de impressão de dedos apresenta uma relação complexa altamente incomum de um hospedeiro especifico (P. trifoliata), um viroide específico (CVd-IIIb), o fator climático (água) e uma prática cultural específica (irrigação por aspersão). Vernière et al. (2004) não observaram sintomas de impressão de dedos em $P$. trifoliata associados à infecção com CVd-III, o que indica que tais sintomas não são persistentes ou desaparecem depois de 10 anos. O CVdIII induz o ananicamento de combinações cítricas, existindo especial interesse nesse viroide por não haver relação com nenhuma doença em espécies e cultivares comerciais (Semancik et al., 1997).

O sintoma típico de exocorte em porta-enxerto de trifoliata, ou seja, presença indesejável de rachaduras, esteve associado à maior concentração de CEVd em 3 das 7 amostras, as quais também apresentavam sintomas visuais de descamamento em campo (Targon et al., 2006). O limão 'Cravo' utilizado como porta-enxerto, é a única espécie comercial descrita como sintomática à exocorte e xiloporose (Moreira, 1955; 1959). Entretanto, a relação causa-efeito somente foi confirmada para o HSVd (Reanwarakorn \& Semancik, 1999b) e pouco se sabe sobre a reação desta espécie à infecção por outros viroides dos citros (Rodrigues et al., 1999). Barbosa \& Duran-Vila (2005), avaliando o comportamento do limoeiro 'Cravo' à inoculação com diferentes espécies de viroides dos citros, observaram, em análises de sPAGE e hibridização, que o limoeiro ‘Cravo' foi suscetível à infecção pelo CEVd, CBLVd, HSVd (variantes IIa, IIb e IIc), CVd-III e CVd-IV, já que foi possível detectar esses viroides nos tecidos das plantas inoculadas.. O estudo de Barbosa \& Duran-Vila (2005) foi efetuado com plantas obtidas de semente e a resposta à infecção por viroides pode ser diferente quando o limão 'Cravo' for utilizado como porta-enxerto. Plantas de 'Cravo' inoculadas com CEVd apresentavam zonas amareladas na casca dos ramos secundários $\mathrm{e}$ as inoculadas com $\mathrm{CVd}-\mathrm{IV}$ induziram o aparecimento de rachaduras na casca do ramo principal e secundários. As plantas inoculadas com a mistura de viroides apresentaram enfezamento, ramos amarelados, com rachaduras e folhas pequenas (Barbosa \& Duran-Vila, 2005; Barbosa et al., 2005a). O amarelecimento de ramos, observado como resposta à inoculação com o CEVd, já havia sido relatado anteriormente como "yellow blotching". Este era o sintoma considerado característico em 'Cravo' 
utilizado como planta indicadora de exocorte (Salibe, 1961), quando ainda não se tinha estabelecido o agente causal da doença. A presença de rachaduras em 'Cravo' como portaenxerto tinha sido descrita anteriormente e considerava-se como uma das manifestações de exocorte (Salibe, 1961). No Brasil, a presença do CEVd associou-se de maneira clara a sintomas de descamamento, enquanto a ausência deste sintoma e a presença de nanismo se associou à infecção por outros viroides distintos do CEVd em limoeiro 'Cravo' (Rodrigues et al., 1999). Silva (2007) observou o sintoma clássico da exocorte em porta-enxerto de 'Cravo' de plantas infectadas com CEVd e a ocorrência de outros dois tipos de sintomas, que foram observados em plantas infectadas com CEVd, CEVd + HSVd, CEVd + CVd-III e CEVd + HSVd + CVd-III, indicando não haver associação direta das diferentes combinações de viroides com os sintomas observados.

Vernière et al. (2006) verificaram que o desempenho de árvores de 'Clementina' enxertadas sobre P. trifoliata infectadas com combinações de viroides contendo CEVd, CVd-III ou ambos foi significativamente menor comparados ao controle sem inocular, em termos de altura, circunferência de copa e porta-enxerto e produção acumulada. Cada efeito foi maior e apareceu mais cedo em árvores infectadas com combinações múltiplas de viroides que nas árvores infectadas com um único viroide. Entretanto, seu efeito no desempenho das plantas não foi adicional, revelando um antagonismo. A natureza da interação entre dois viroides pode ser interpretada diferentemente se viroides adicionais estiverem presentes ou não.

\section{Características biológicas e moleculares dos viroides de citros}

Os viroides de citros foram, inicialmente, divididos em cinco grupos de acordo com sua mobilidade eletroforética em géis de poliacrilamida (PAGE), homologia de sequência (deduzida por técnicas de hibridização), círculo de hospedeiros e expressão de sintomas em cidra 'Etrog' (Duran-Vila et al., 1988a; Semancik \& Duran-Vila, 1990). Entretanto, com a elucidação das sequências genômicas dos diferentes viroides, estes passaram a ser denominados de acordo com as novas regras de taxonomia estabelecidas para vírus e viroides, sendo classificados em Famílias, Gêneros, Espécies e Variantes [ver, para maiores detalhes, o capítulo referente aos viroides na última publicação do Comitê Internacional de Taxonomia de Vírus (ICTV) (Flores et al., 2005b)]. Segue descrição de cada uma das espécies de viroides de citros, suas características biológicas e moleculares, bem como sua classificação taxonômica:

\section{Citrus exocortis viroid (CEVd)}

O início do estudo dos viroides se deu em 1971 com a publicação de T.O. Diener descrevendo o Potato spindle tuber viroid, PSTVd [viroide causador do afilamento do tubérculo da batata (Solanum tuberosum L.)] como o representante de uma nova classe de fitopatógenos com características moleculares e evolutivas distintas dos vírus de plantas: os viroides (Diener, 1971, 1991). Um ano depois, J.S. Semancik e L.G. Weathers demonstraram que a doença da exocorte dos citros, conhecida desde meados do século 20 como de provável etiologia viral (Fawcet \& Klotz, 1948; Benton et al., 1949; Moreira, 1955, 1959), também era causada por um viroide: denominado de Citrus exocortis viroid (CEVd) (Semancik \& Weathers, 1972a). A sequência genômica do CEVd foi elucidada somente 10 anos mais tarde (Gross et al., 1982; Visvader \& Symons, 1985; Visvader et al., 1982), sendo que hoje em dia, um enorme número de variantes do CEVd têm suas sequências publicadas e disponibilizadas em bancos internacionais de dados.

Variantes do CEVd apresentam genoma com aproximadamente 370 nucleotídeos (nt.) e, atualmente, em função de características biológicas e moleculares, são classificados como pertencentes ao gênero Pospiviroid, família Pospiviroidae (Flores et al., 2005b). Assim como outros membros desse gênero, apresentam molécula de RNA com conformação do tipo bastão com forte estrutura secundária (devido aos pareamentos entre as bases), uma região central conservada (CCR) e uma região terminal conservada (TCR), assim como os cinco domínios descritos por Keese \& Symons (1985): terminal esquerdo ("terminal left”, TL), patogenicidade (P), central (C), variável (V) e terminal direito ("terminal right", TR) (Figura 2).

O CEVd apresenta um amplo círculo de hospedeiros podendo infectar plantas de importância econômica de outras famílias botânicas distantes evolutivamente de Rutaceae, como tomateiro, berinjela, cenoura, videira, entre outras. CEVd pode induzir diferentes tipos de sintomas que vão desde distorção e epinastia foliar, nanismo e necrose em tomateiro [doença conhecida por "bunchy top" (Mischra et al., 1991)], a uma total ausência de sintomas (latência) em berinjela, cenoura, videira e Vicia faba L. (Fagoaga \& Duran-Vila, 1996; Garcia-Arenal et al., 1987; Gandía et al., 2007).

Em citros, o impacto econômico da presença do CEVd é dependente da combinação copa/porta-enxerto. Em climas mais amenos, árvores infectadas com CEVd enxertadas sobre Citrange carrizo podem exibir amarelecimento generalizado da copa, declínio e desenvolvimento limitado, mesmo na ausência dos sintomas típicos de exocorte (descamação da casca). Nos países em que o porta-enxerto laranja azeda foi substituído por P. trifoliata ou por híbridos de Citrange, as estratégias para a obtenção de matrizes e borbulhas livres de viroides foram implantadas.

CEVdé o agente causal da doença exocorte dos citros, porém, após a descoberta da ocorrência de novos viroides em citros, muitos ocorrendo em infecções múltiplas, surgiu o questionamento da possibilidade dos outros viroides também induzirem exocorte. Estudos posteriores comprovaram que o CEVd é o único viroide capaz de induzir individualmente a exocorte em P. trifoliata, apesar de que Ito et al. (2002) demonstraram que uma combinação de diferentes viroides, 
na ausência do CEVd, foi capaz de induzir sintomas do tipo exocorte em cidra (C. medica L.) enxertada sobre $P$. trifoliata. Vernière et al. (2006) também demonstraram que sintomas de exocorte podem ser induzidos por combinações de viroides, sem a presença de CEVd.

O sequenciamento de um enorme número de isolados de CEVd tem mostrado que plantas infectadas contêm uma população de variantes de sequência que seguem o modelo de quasispecies, ou seja, uma população heterogênea de moléculas de RNA similares, quase idênticas, derivadas de mutações pontuais devido à ausência de mecanismos de correção nas RNA polimerases (Visvader \& Symons, 1985; Palacio \& Duran-Vila, 1999; Gandía et al., 2000, 2005; Chaffai et al., 2007). Hospedeiros e até mesmo tecidos distintos da planta podem ser determinantes na seleção de variantes de sequência com reflexos diretos na expressão de sintomas e severidade (Semancik et al., 1993; Gandía et al., 2007).

Atualmente, o CEVd é um dos viroides mais bem caracterizados em termos de estrutura, replicação, círculo de hospedeiros e propriedades biológicas. Isso se deveu principalmente à possibilidade de utilização de plantas hospedeiras experimentais herbáceas como tomateiro e Gynura aurantiaca. Apesar de haver poucos dados sobre as relações entre sequência de nucleotídeos e expressão de sintomas, Visvader \& Symons $(1985,1986)$ propuseram uma classificação de variantes de CEVd em severas (Classe A) e fracas (Classe B), de acordo com propriedades biológicas, verificadas quando inoculadas em tomateiros, as quais diferem em pelo menos 26 nucleotídeos, principalmente em duas regiões denominadas $P_{L}$ (no domínio $\mathrm{P}$ ) e $\mathrm{P}_{\mathrm{R}}$ (no domínio V). O papel do domínio $\mathrm{P}$ na modulação da expressão dos sintomas em tomateiros foi verificado por meio de inoculações de plântulas com quimeras entre Tomato apical stunt viroid (TASVd) e CEVd (Owens et al., 1990), assim como o papel do domínio TL, analisando-se porções genômicas maiores (Sano et al., 1992). A inoculação de quimeras entre HSVd e CEVd também sugeriu um papel importante do domínio TR na patogenicidade (Sano \& Ishiguro, 1998). Esses resultados indicam que fatores relacionados com a patogenicidade devam estar distribuídos em diferentes porções da molécula do $\mathrm{CEVd}$, sendo difícil associá-los a simples mutações ou regiões genômicas. O hospedeiro também deve estar diretamente associado com determinantes moleculares e expressão de sintomas, conforme observaram Skoric et al. (2001) ao analisarem o comportamento de CEVd em $G$. aurantiaca, sendo identificados variantes distintos quanto à severidade, modulados por 5 nucleotídeos no domínio $\mathrm{P}$, resultados não consistentes com os previamente obtidos em tomateiros (Visvader \& Symons, 1985). Variantes de CEVd que apresentam duplicações no domínio TR têm sido identificados ocorrendo naturalmente em berinjela (Fadda et al., 2003) e em tomateiro (Szychowski et al., 2005). Esses variantes de sequência, que chegam a apresentar genoma com até 475 nucleotídeos (cem nucleotídeos a mais do que os isolados de CEVd normalmente possuem), parecem estar associados a fatores inerentes ao hospedeiro e também ao tempo prolongado de infecção. De qualquer forma, torna-se muito difícil extrapolar os resultados obtidos até o momento com hospedeiros herbáceos para o patossistema citrosCEVd, principalmente devido a este patógeno, em citros, induzir sintomas totalmente distintos daqueles observados em tomateiro e Gynura. Fica aqui mais um desafio para os pesquisadores.

\section{Hop stunt viroid (HSVd)}

Tanto a "xiloporose" dos citros, descrita pela primeira vez em lima doce (C. limettioides) na Palestina (Reichert \& Perlberger, 1934), como a "cachexia", descrita por Childs (1950) em tangelo 'Orlando' (C. paradisi x C. reticulata), correspondem à mesma doença, induzida por variantes patogênicos do Citrus viroid II (CVd-II) (Reanwarakorn \& Semancik, 1998, 1999a), denominado inicialmente de Citrus cachexia viroid (CCaVd) (Semancik et al., 1988). Porém, com a caracterização biológica e sequenciamento de diversos isolados de Hop stunt viroid (HSVd), verificou-se que todos os isolados de CVd-II tratavam-se de variantes do HSVd, tanto os que não causavam sintomas em citros (Sano et al., 1988), como aqueles que eram capazes de induzir a xiloporose (ou cachexia) (Levy \& Hadidi, 1993; Semancik et al., 1988).

A xiloporose caracteriza-se por descoloração, exsudação de goma e bronzeamento dos tecidos do floema, fendas e descascamento, sintomas esses observados principalmente em tangelo 'Orlando' (Childs, 1950). Porém, outras variedades e espécies comerciais são sensíveis como mandarinas e híbridos (tangors e tangelos) e kumquats (Fortunella sp.).

O CVd-II foi, inicialmente, subdividido em CVdIIa e CVd-IIb, em função de apresentarem mobilidade eletroforética distinta (Duran-Vila et al., 1988a). O CVdIIa, por apresentar título baixo e, principalmente, por não induzir sintomas visíveis que levassem a prejuízos para a cultura dos citros, foi propagado e disseminado para praticamente todas as regiões citrícolas do mundo. Entretanto, sabe-se que esses variantes (CVd-IIa) parecem também afetar o desenvolvimento das árvores, induzindo sintomas leves de descamação da casca somente em portaenxerto de $P$. trifoliata, além de afetar o desenvolvimento da copa (Roistacher et al., 1993). Porém, a constatação de que a doença xiloporose era induzida somente por variantes do CVd-IIb (CCaVd) (Semancik et al., 1988), e não por variantes do CVd-IIa, foi interessante por definir a existência de duas moléculas com sequência de nucleotídeos quase idêntica, porém apresentando comportamento biológico distinto. Análises comparativas dos genomas de diversos variantes de CVd-IIa e CVd-IIb revelaram que apenas seis nucleotídeos localizados no domínio "V" eram responsáveis pela patogenicidade do HSVd em citros (Reanwarakorn \& Semancik, 1998). O mais interessante é que a importância desses seis nucleotídeos parece estar mais relacionada com 
a alteração da estrutura secundária e geometria da molécula do RNA do HSVd do que com as mutações pontuais (Palacio-Bielsa et al., 2004; Serra et al., 2008c).

Todos os variantes de CVd-II (HSVd) induzem sintomas de nanismo e rugosidade foliar em pepino (Cucumis sativus L.) e diferentes graus de severidade de sintomas em cidra 'Etrog', entretanto, somente os variantes que induzem xiloporose causam sintomas em tangerineira 'Parson's Special', tangelo 'Orlando' e 'Alemow' (PalacioBielsa et al., 2004), sendo essas plantas sistemas biológicos de extrema utilidade para a identificação desses variantes.

Em resumo, podem-se definir, em função de características biológicas e moleculares, dois grupos distintos de variantes do HSVd: (i) aqueles que apresentam infecção latente em hospedeiros sensíveis à xiloporose (inicialmente denominados de CVd-IIa); (ii) e aqueles que induzem xiloporose (inicialmente denominados CVd-IIb).

Variantes do HSVd apresentam genoma com tamanho entre 294 e 303 nucleotídeos e, atualmente, em função de características biológicas e moleculares, correspondem à única espécie (espécie-tipo) descrita do gênero Hostuviroid, família Pospiviroidae (Flores et al., 2005b). Apresentam conformação do tipo bastão com forte estrutura secundária, uma região central conservada (CCR) e uma forquilha terminal conservada $(\mathrm{TCH})$, além dos cinco domínios descritos anteriormente para o CEVd (Figura 2).

\section{Citrus bent leaf viroid (CBLVd)}

O Citrus bent leaf viroid (CBLVd), inicialmente denominado Citrus viroid I (CVd-I) e, atualmente, classificado como pertencente ao gênero Apscaviroid, família Pospiviroidae, parece ser resultado de uma combinação de porções do domínio C do Apple scar skin viroid (ASSVd), espécie tipo dos apscaviroides, com porções genômicas (dos domínios P e TL) do CEVd (Ashulin et al., 1991).

CBLVd é um viroide que, normalmente, não causa sintomas na maioria das espécies e variedades cultivadas de citros, porém induz sintomas moderados de epinastia foliar e pontos necróticos nas nervuras centrais de folhas de cidra 'Etrog', que leva a uma intensa curvatura das folhas (sintoma que dá nome ao viroide), além de pequenas depressões que podem ser vistas abaixo da casca, no tronco (Duran-Vila et al., 1986, 1993). Pequenas depressões no tronco, nanismo pouco pronunciado e redução do volume da copa também têm sido observados em árvores enxertadas sobre $P$. trifoliata (Roistacher et al., 1993; Semancik et al., 1997). O círculo de hospedeiros do CBLVd é restrito a membros da família Rutaceae, com exceção da transmissão experimental via enxertia para abacateiro (Persea americana L.) (Hadas et al., 1992).

Inicialmente, o CVd-I foi descrito como dois viroides independentes denominados de CVd-Ia e CVd$\mathrm{Ib}$ por apresentarem migração distinta em PAGE (DuranVila et al., 1988b). Porém, experimentos de hibridização e análise das sequências comprovaram que os viroides (CVd-Ia e Ib) tratavam-se de variantes da mesma espécie
(CVd-I ou CBLVd), sendo que CVd-Ia apresentava 327 nt., enquanto que CVd-Ib tinha uma molécula de RNA com 318 nt. Foissac \& Duran-Vila (2000) concluíram que CVd-Ia, CVd-Ib e CBLVd, por apresentarem o mesmo comportamento biológico, compartilharem mais de $90 \%$ de similaridade de sequência e muitas vezes co-existirem no mesmo hospedeiro como populações de variantes de sequência, deveriam ser considerados como variantes de uma mesma espécie. Estudos de variabilidade genética demonstraram que um variante de CBLVd (II), quando inoculado isoladamente em plantas de cidra 'Etrog', também seguia o modelo de quasispecies, apresentando populações de moléculas quase-idênticas (Gandía \& Duran-Vila, 2004). Hataya et al. (1998), ao compararem as sequências de diferentes isolados do CVd-I, propuseram que o CVdIa derivou de CVd-Ib. Ito et al. (2000) descreveram um possível novo viroide denominado de CVd-I-LSS (Low Sequence Similarity). Porém, suas características biológicas e moleculares o classificaram como mais um variante de sequência do CVd-I (CBLVd).

\section{Citrus dwarfing viroid (CDVd)}

$\mathrm{O}$ Citrus dwarfing viroid (CDVd), inicialmente denominado de Citrus viroid III (CVd-III), apresenta genoma com 294 nucleotídeos e em função de características biológicas e moleculares pertence ao gênero Apscaviroid, família Pospiviroidae (Flores et al., 2005b). Inicialmente, o CVd-III foi descrito como dois viroides independentes (CVd-IIIa e CVd-IIIb), que apresentavam comportamentos distintos em PAGE (Duran-Vila et al., 1988b). Posteriormente, análises envolvendo hibridização (Semancik \& Duran-Vila, 1991) e sequenciamento (Rakowski et al., 1994) revelaram que se tratava de variantes do mesmo viroide. Além disso, o CVdIII apresenta regiões genômicas que parecem ser derivadas de porções conservadas do PSTVd e do ASSVd (Stasys et al., 1995). Embora o CVd-III pareça apresentar um genoma conservado quando se analisam plantas de citros no campo, esse viroide também segue um modelo de quasispecies (Owens et al., 1999, 2000).

CVd-III possui um círculo de hospedeiros restrito à Rutaceae. Em cidra 'Etrog', induz anelamento e necrose do pecíolo com consequente queda de folhas. Redução significativa do tronco e do volume de copa foi descrita em laranja 'Valencia' enxertada sobre P. trifoliata (Roistacher et al., 1993). Porém, apesar da redução do porte, a relação entre o rendimento de frutos e o volume da copa foi elevada, indicando que esse viroide apresentava-se como um bom candidato para ser utilizado como agente para a diminuição do porte das plantas de citros (Gillings et al., 1991; Semancik et al., 1997). Em função dessa característica, Vernière et al. (2004) sugeriram a adoção da nomenclatura de Citrus dwarfing viroid (CDVd) em substituição ao CVd-III. Aspectos relacionados à utilização de viroides como agentes para a diminuição do porte de árvores serão abordados mais adiante. 
Viroides em citros
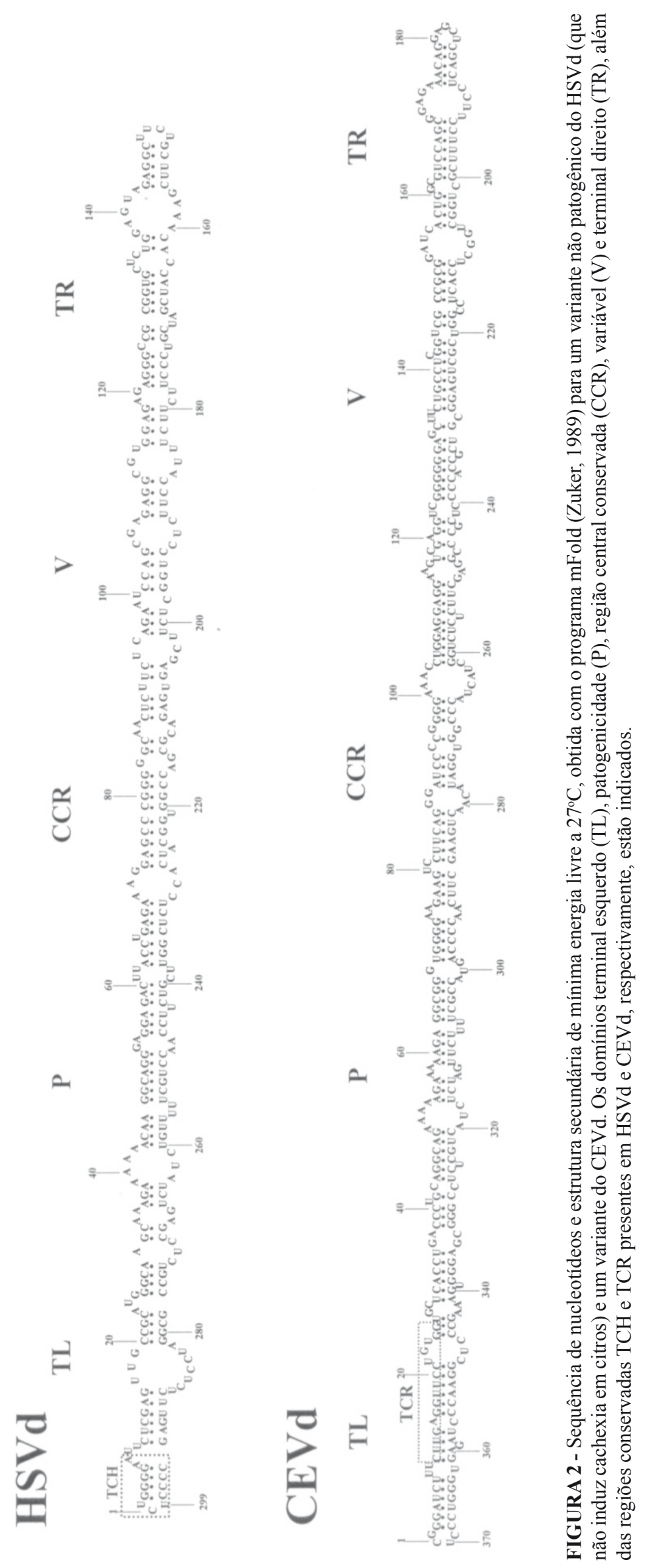

Tropical Plant Pathology 34 (5) September - October 2009 


\section{Citrus bark cracking viroid (CBCVd)}

Dos viroides de citros, o Citrus bark cracking viroid (CBCVd), previamente denominado Citrus viroid IV (CVd-IV), é o que apresenta a menos expressiva distribuição mundial, ocorrendo na Califórnia, EUA (Duran-Vila et al., 1988a), Israel (Hadas et al., 1989) e Turquia (Önelge et al., 2000), e considerado raro na Europa (Pallás et al., 2003). Os sintomas induzidos por esse viroide em árvores de Clementina enxertadas sobre $P$. trifoliata são de rachaduras severas no tronco, sendo verificado um efeito sinérgico quando o $\mathrm{CBCVd}$ foi coinoculado com HSVd (Vernière et al., 2006).

Atualmente, o $\mathrm{CBCVd}$ pertence ao gênero Cocadviroid [a espécie tipo desse gênero é o Coconut cadan-cadang viroid (CCCVd)], família Pospiviroidae (Flores et al., 2005b). Porém, sua posição taxonômica tem sido questionada em função das seguintes argumentações: (i) o CBCVd apresenta relacionamento filogenético com alguns isolados de CEVd; (ii) CEVd e $\mathrm{CBCVd}$ apresentam características biológicas similares; (iii) análise cuidadosa de alguns "motivos" estruturais e genômica comparativa indicam que o CBCVd está mais próximo de CEVd do que de CCCVd (Semancik \& Vidalakis, 2005). O CBCVd apresenta molécula de RNA com 284 nucleotídeos, contendo uma porção de 80 a 90 resíduos (nos domínios $\mathrm{V}$ e TR) idêntica ao CEVd (Puchta et al., 1991). Além disso, em um elegante e extenso trabalho de inoculação de diferentes viroides em plantas de citros e avaliação da expressão dos sintomas e desempenho das plantas no campo, Vernière et al. (2006) observaram efeito antagônico em plantas co-infectadas com CBCVd e CEVd, havendo uma atenuação nos sintomas normalmente induzidos pelo CEVd. Este antagonismo reforça a existência de uma forte relação biológica entre esses dois viroides. Esta é mais uma questão que aguarda solução por parte dos "viroidologistas".

\section{Novos viroides em citros: Citrus viroid original source (CVd-OS) e Citrus viroid V (CVd-V)}

Em 2001, um novo viroide de citros denominado CVd-OS (Citrus viroid - original source) foi descrito no Japão (Ito et al., 2001). O viroide apresenta características moleculares que o classificam como possível membro do gênero Apscaviroid: (i) genoma com 330 nt.; (ii) 68\% de identidade com CVd-III, viroide que apresentou maior identidade de sequência. Embora apresente características moleculares dos apscaviroides de citros, os sintomas induzidos em citros são distintos dos outros viroides desse gênero. Esse viroide parece estar restrito ao Japão. A denominação "OS" é regional e não obedece aos critérios de nomenclatura do ICTV.

Em 2008, um novo viroide de citros denominado Citrus viroid V (CVd-V) foi identificado e caracterizado na Espanha (Serra et al., 2008a). O CVd-V deverá ser incluído como mais um membro do gênero Apscaviroid: (i) por apresentar genoma constituído de um RNA circular com 294 nt.; (ii) apresentar a CCR característica dos apscaviroides, e a TCR presente em outros membros da família Pospiviroidae; (iii) estrutura secundária estável com conformação do tipo bastão com $68 \%$ de pareamento entre as bases; (iv) identidade de sequência menor que $90 \%$ com outros viroides; (v) induzir sintomas específicos em cidra. Além disso, quando o $\mathrm{CVd}-\mathrm{V}$ foi co-inoculado em cidra com outros apscaviroides (CBLVd e CVd-III), houve a manifestação de efeito sinérgico com nanismo pronunciado, além de epinastia e necrose das nervuras, sintomas estes não observados quando o $\mathrm{CVd}-\mathrm{V}$ foi inoculado isoladamente. $\mathrm{O}$ $\mathrm{CVd}-\mathrm{V}$, quando inoculado em cidra isoladamente, induziu leve nanismo e sintomas de necrose e rachadura nos ramos (Serra et al., 2008a).

A origem desse viroide não está clara, porém um detalhe interessante é que o CVd-V foi isolado de plantas de Atalantia citroides Pierre ex. Engl. \& Prantl, um hospedeiro que se caracteriza por ser resistente aos demais viroides conhecidos (Barbosa et al., 2005b; Serra et al., 2008a). Em função de apresentar mobilidade eletroforética similar ao HSVd e CVd-III, sua detecção por sPAGE pode ter sido mascarada. Isso foi evidenciado em levantamento de sua distribuição, que parece ser maior do que se pensava, uma vez que foi detectado nos EUA, Espanha, Nepal e Sultanato de Oman, sendo caracterizados três variantes de sequência, em diferentes espécies e variedades de citros. Além disso, todas as espécies e variedades de citros e gêneros afins são hospedeiros em potencial do CVd-V (Serra et al., 2008b).

\section{ORIGEM, EPIDEMIOLOGIA E CONTROLE}

A origem dos viroides em citros é difícil de determinar, uma vez que não há fósseis desses patógenos que permitam extrapolar o tempo de sua existência na Terra. Porém as evidências mais antigas foram encontradas no piso de uma sinagoga no Norte de Negev, Israel, onde há decorações com frutos de citros mal formados, característicos de infecções por CEVd, sugerindo que a coinfecção dos cítricos com viroides existe há pelo menos 2 mil anos (Bar-Joseph, 2003).

Os viroides de citros têm sua disseminação totalmente dependente das práticas agrícolas, com especial ênfase para a enxertia de borbulhas infectadas e o trânsito e intercâmbio internacional de material infectado. Além disso, o número de espécies e variedades cultivadas no mundo é bastante limitado e homogêneo, o que aliado à não expressão de sintomas (latência) de plantas de citros infectadas por viroides, facilitou a disseminação desses patógenos na totalidade dos países produtores. Portanto, uma vez que os viroides não apresentam vetores, a disseminação desses patógenos é totalmente dependente de ações do homem.

Assim como são recomendadas para os vírus de plantas, as medidas preventivas são as mais importantes e efetivas para o controle dos viroides. A utilização de material de propagação vegetativa sadio é fundamental, porém 
está diretamente associada ao bom desempenho de outras medidas, tais como: (i) redução do trânsito de materiais propagativos a partir de áreas de ocorrência do patógeno; (ii) programas de indexação e certificação (ver detalhes mais adiante); (iii) serviços de quarentena rigorosos com métodos de detecção que apresentem elevada sensibilidade; (iv) acompanhamento das plantas em viveiros e também da cultura e eliminação de plantas infectadas; (v) desinfecção de ferramentas com hipoclorito de sódio; (vi) separação física de plantas infectadas e sadias; (vii) evitar o emprego de variedades de copa e porta-enxerto suscetíveis (DuranVila \& Semancik, 2003).

\section{MÉTODOS DE DETECÇÃO}

Os métodos de detecção dos viroides podem ser subdivididos em biológicos e moleculares. Para fins de detecção molecular, é importante levar em consideração que o material genético dos viroides é RNA de fita simples, circular e fortemente estruturado, e que esses patógenos não possuem envoltório proteico. Deste modo, descartamse os métodos imunológicos utilizados normalmente para a detecção de vírus, como ELISA.

\section{Métodos Biológicos}

Os citros são hospedeiros de vários viroides. No entanto, há hospedeiros alternativos que acumulam esses patógenos em maiores concentrações e que podem servir como indicadores. No Estado de São Paulo, Moreira (1954) observou sintomas de exocorte em limoeiro 'Cravo', sendo este utilizado como indicador nas fases iniciais de indexação biológica. A subsequente indexação em $P$. trifoliata no campo foi baseada em sintomas no tronco, até que a doença foi transmitida para cidreira, que se tornou a indicadora mais rápida em condições de casa de vegetação (Salibe, 1961; Calavan et al., 1964).

A indexação biológica, visando determinar se plantas estão ou não infectadas pelo viroide da exocorte, é realizada nos clones RMA 861 ou RMA 861-S1 de cidreira 'Etrog' enxertados em porta-enxerto de 'Cravo', utilizando-se o teste de dupla enxertia. Embora algumas vezes os sintomas já possam ser observados quando ocorre a primeira brotação da gema indicadora de cidra, o mais comum é que se manifestem dois meses após a inoculação, em temperaturas de 28 a $32^{\circ} \mathrm{C}$, e consistem em epinastia do ápice, encarquilhamento das folhas (Figura 1E), escurecimento de nervuras secundárias e amarelecimento em estrias no caule. A indexação biológica para cachexia/ xiloporose foi feita, inicialmente, na indicadora tangerineira 'Parson's Special' em porta-enxerto de limoeiro 'Cravo', pela técnica de dupla enxertia. O híbrido Clemelin 11-20 [C. sinensis (L.) Osb. x C. reticulata], um híbrido entre laranjeira 'Hamlin' e tangerineira 'Clementina', em portaenxerto de 'Cravo', tem sido apontado como o indicador com melhor desempenho (Pérez et al., 1992). Nesse híbrido, nas condições do Estado de São Paulo, em temperaturas de 28 a $32^{\circ} \mathrm{C}$, o início dos sintomas se dá a partir dos seis meses após a inoculação, $100 \%$ dos sintomas aos dez meses, com ganho de seis meses quando comparado com a tangerineira 'Parson's Special' (Carvalho et al., 2003a). Os sintomas observados são caneluras no tronco, impregnação de goma na casca, saliências no lenho, reentrâncias na casca do tronco da indicadora, próxima à região de enxertia.

Apesar de cidra 'Etrog' ser utilizada na indexação biológica para a presença do CEVd, os outros viroides de citros também induzem sintomas nessa indicadora (DuranVila \& Semancik, 2003). A Tabela 2 apresenta um resumo das reações produzidas pelas espécies de viroides em cidra 'Etrog'. Podem ser observadas reações diferentes devido ao fato de existirem misturas de espécies de viroides nas plantas de campo, e esses viroides poderem interagir entre si produzindo reações diferentes das já descritas. $\mathrm{O}$ método biológico permite que seja feito o diagnóstico da infecção por viroides, mas não permite determinar quais espécies de viroides se encontram na amostra analisada. Na Figura 1B observa-se o sintoma de epinastia induzido por CEVd em cidra.

Métodos alternativos, combinando microenxetia in vitro com indexação biológica em plantas indicadoras para o viroide da exocorte foram avaliados por Kapari-Isaia et al. (2008). Em contraste com a indexação clássica, na qual

TABELA 2 - Sintomas induzidos por espécies de viroides dos citros em cidra 'Etrog Arizona 861-S1'

\begin{tabular}{llllcc}
\hline \hline Viroide & Nanismo & Epinastia & \multicolumn{3}{c}{ Necrose } \\
& & & Nervura & Pecíolo Vértice das folhas \\
\hline CEVd & Acentuado & Severa & Geral & + & - \\
CBLVd & Leve & Leve & Pontual & - & - \\
HSVd & - & - & - & $+/-$ & $+/-$ \\
CVd-III & Moderado & Geral & Geral & + & - \\
CVd-IV & Moderado & Geral & Geral & + & - \\
CVd-OS & - & Leve & - & + & - \\
CVd- ${ }^{*}$ & Leve & Leve & Pontual & + & - \\
\hline
\end{tabular}

$+=$ presença de sintomas; - = ausência de sintomas

Adaptado de Bielsa (1999) e Duran-Vila \& Semancik (2003)

*Serra et al. (2008a) 
a expressão dos sintomas na indicadora ocorreu de 11 a 14 semanas após a inoculação, a microindexação in vitro com plântulas ou microestacas de cidra inoculadas por garfagem, permitiu o diagnóstico em 12 e 20 dias após inoculação, respectivamente. A indexação de microestacas por inoculação por meio de injeção apresentou resposta mais lenta, demorando 40 dias para a expressão dos sintomas.

Finalmente, merece destaque o teste de proteção cruzada (cross-protection), um método indireto de indexação biológica (Duran-Vila \& Semancik, 1990). Com esse método, é possível se detectar infecções latentes ou induzidas por isolados fracos. A inoculação prévia de uma planta indicadora com um isolado fraco (não virulento) de um viroide protege ou retarda o aparecimento dos sintomas quando a mesma planta é posteriormente desafiada por um isolado severo (virulento) do mesmo viroide. Portanto, nesse caso, o aparecimento de um sintoma severo na planta indicadora significa ausência do isolado fraco. Os mecanismos moleculares envolvidos na proteção cruzada ainda não são bem conhecidos, mas provavelmente estejam relacionados com silenciamento de RNA (Carbonell et al., 2008; Gomez et al., 2009).

\section{Métodos moleculares}

A transmissão de isolados severos causadores de exocorte para a espécie herbácea $G$. aurantiaca tornou possível o isolamento e caracterização do agente causador da doença, o CEVd (Semancick \& Weathers, 1972a). A partir dessa informação, vários métodos para identificação de outras espécies de viroides de citros, bem como para detecção, foram desenvolvidos. Na maioria dos métodos, a extração de RNAs totais é determinante para os procedimentos posteriores como nas técnicas de eletroforese em géis de poliacrilamida (PAGE), RT-PCR e hibridização.

\section{Extração de RNA}

Há muitos protocolos de extração de RNAs que variam de acordo com as características do hospedeiro e dos tecidos a serem analisados. Não há um método universal aplicável para qualquer situação, sendo que para cada caso deverá se escolher aquele mais adequado. $\mathrm{Na}$ maioria das vezes, faz-se necessário promover o aumento da concentração dos viroides de citros com a inoculação prévia em cidreira durante 1-2 meses antes da extração de RNAs. Essa hospedeira promove uma bio-amplificação do título de todas as espécies de viroides conhecidas (DuranVila et al., 1988a; Roistacher et al., 1977).

Dentre os protocolos de extração de RNAs viroidais, o método descrito por Semancik (1986) com algumas modificações pode ser utilizado para a maioria das plantas cultivadas que apresentem um baixo nível de compostos deletérios. Folhas (normalmente 10 gramas) são homogeneizadas em presença de tampão de extração (0,4M de Tris- $\mathrm{HCl} \mathrm{pH} 8,9,1 \%$ de SDS, 5mM de EDTA, $4 \%$ de mercaptoetanol) contendo fenol saturado em água ( $\mathrm{pH} 7,0)$, na proporção de 1:5 (g:v). Em seguida, os ácidos nucleicos presentes na fase aquosa são submetidos a uma cromatografia em celulose não-iônica (CF-11) em presença de etanol. A seguir, são precipitados em presença de isopropanol e ressuspendidos em água estéril. Caso a preparação de ácidos nucleicos ainda apresente viscosidade elevada, principalmente devido à presença em excesso de polissacarídeos, pode-se empregar um método para reduzir a concentração desses compostos, baseado em extração com metoxietanol (Bellamy \& Ralph, 1968).

Outros métodos de extração de RNAs podem ser utilizados como: (i) o que permite a obtenção de grande concentração de viroides, descrito por Semancik et al. (1975); (ii) o que utiliza o reagente TRIZOL (Invitrogen) (Targon et al., 2005); (iii) o que utiliza SDS/acetato de potássio (Astruc et al., 1996; Cañizares et al., 1998). Todos os métodos permitem a obtenção de RNAs de boa qualidade, no entanto, Bernad \& Duran-Vila (2006) apontam algumas vantagens no uso do método SDS/acetato de potássio, tais como: (i) não há necessidade de usar solventes orgânicos; (ii) economia e praticidade; (iii) a homogeneização das amostras em sacos plásticos fechados diminui a chance de contaminação cruzada. A escolha do método vai depender do uso dos RNAs.

\section{Eletroforese sequencial em géis de poliacrilamida (sPAGE)}

A mobilidade eletroforética de uma molécula é determinada principalmente por três fatores: (i) carga; (ii) tamanho; e (iii) conformação (Sambrook \& Russel, 2001). Os viroides, por serem pequenas moléculas de RNA circular, apresentam características peculiares quando submetidos à eletroforese. Sua migração em géis de poliacrilamida (PAGE) nativos tem um comportamento similar aos de DNA de fita dupla lineares com mesmo número de bases. Porém, quando são submetidos a uma eletroforese em condição desnaturante (presença de ureia ou temperatura acima de $70^{\circ} \mathrm{C}$ ), por perderem as pontes de hidrogênio que garantem a forte estrutura secundária, passam a apresentar uma conformação circular "relaxada". Em função disso, as moléculas de RNA têm um retardamento na migração, permanecendo separados dos demais RNAs lineares presentes na planta (como os pequenos RNAs ribossomais) e dos monômeros e oligômeros lineares viroidais (moléculas oriundas da replicação viroidal) [para saber mais sobre replicação dos viroides, consultar a revisão de Flores et al. (2005a)].

Os viroides são, então, analisados em PAGE. Há muitas variações de protocolos para análise de viroides e outros pequenos RNAs em PAGE. Porém, nesta oportunidade será abordado somente a utilização do PAGE sequencial (sPAGE), que consiste na realização de uma eletroforese em condição nativa seguida de uma segunda eletroforese em condição desnaturante. Preparações de RNAs contendo viroides são aplicadas em um gel de poliacrilamida nativo $5 \%$ (em TAE 1X) e submetidas à eletroforese por uma hora 
a 100 volts e $70 \mathrm{~mA}$. Após a eletroforese, o gel é corado com brometo de etídeo, e sob luz ultravioleta promove-se o corte (horizontal) de uma porção do gel correspondente à região onde migram os RNAs com tamanho entre $240 \mathrm{e}$ 450 nucleotídeos [faixa correspondente aos tamanhos do maior (401 nt) e menor (246 nt) viroides conhecidos]. O pedaço do gel cortado é transferido cuidadosamente para um segundo gel (contendo $8 \mathrm{M}$ de ureia), sendo a seguir realizada uma nova eletroforese a $25 \mathrm{~mA}$ por 3 horas em tampão de eletroforese TBE 0,25X. Após a segunda eletroforese (desnaturante), o gel é corado com brometo de etídeo (em alguns casos pode ser corado com nitrato de prata para uma maior sensibilidade) (Semancik, 1991; Sänger et al., 1979). Uma variação da sPAGE é o return PAGE (rPAGE), em que não há necessidade da realização de um segundo gel. A segunda eletroforese (desnaturante) é realizada no próprio gel da primeira eletroforese, invertendose a corrente, elevando-se a temperatura e diminuindo a concentração de sais do tampão (Singh, 1991). Apesar de um pouco mais trabalhoso, o sPAGE permite que se tenham resultados mais limpos, com melhor resolução e separação das bandas dos RNAs viroidais.

Foi por meio de sPAGE que foram identificados e isolados os outros viroides de citros (inoculados em cidra), apresentando sintomas semelhantes aos causados pelo CEVd, porém mais fracos. Esses viroides foram chamados, inicialmente, de variáveis $(\mathrm{CVaV})$, tinham peso molecular menor e pensou-se que eram estirpes moderadas do CEVd (Schlemmer et al., 1985). Esse método ainda é muito utilizado em programas de certificação. Além disso, de todas as técnicas moleculares utilizadas em pesquisa com viroides, somente aquelas baseadas em PAGE não requerem conhecimento prévio da sequência de nucleotídeos. Por meio de sPAGE ou rPAGE, é possível identificar rapidamente se há em uma determinada preparação de ácidos nucleicos moléculas correspondentes a viroides. A versatilidade, sensibilidade, praticidade e o baixo custo dos métodos baseados em PAGE, os colocam como os principais métodos utilizados no estudo de viroides. Porém, quando os viroides são conhecidos, outras técnicas moleculares como hibridização de ácidos nucleicos e RT-PCR podem ser utilizadas, conforme será descrito e discutido a seguir.

\section{RT-PCR (Reverse transcription - Polymerase chain reaction)}

As técnicas RT-PCR e multiplex PCR podem ser utilizadas para a detecção de viroides com elevada sensibilidade e especificidade (Levy et al., 1992; Yang et al., 1992). Com a disponibilidade dos dados de sequência das diferentes espécies de viroides, foram desenhados iniciadores específicos para cada uma delas (Gross et al., 1982; Ohno et al., 1983; Puchta et al., 1991; Rakowski et al., 1994; Astruc et al., 1996; Semancik et al., 1997; Ito et al., 2001; Bernad \& Duran-Vila, 2006). Além disso, atualmente, estão disponíveis sequências de iniciadores específicos para a detecção de isolados fracos e severos de CEVd e de variantes do HSVd que induzem ou não cachexia/xiloporose (Bernad \& Duran-Vila, 2006).

Algumas dificuldades podem ser encontradas ao se utilizar RT-PCR, tais como: (i) amplificação de fragmentos de DNA inespecíficos, principalmente quando o RNA é extraído diretamente de material de campo; (ii) obtenção de resultados falso-negativos em amostras sabidamente infectadas com viroides, que pode ser devido à presenca de inibidores na reação ou a falhas na síntese de cDNA. Bernad \& Duran-Vila (2006) definiram alguns pontos-chave para amplificação eficiente e consistente dos viroides de citros: (i) uso de transcriptase reversa própria para sintetizar cDNA em temperaturas mais altas $\left(65^{\circ} \mathrm{C}\right)$ para evitar a reestruturação da molécula de RNA do viroide; (ii) devem ser utilizados vários pares de iniciadores para a síntese do cDNA e PCR; (iii) a transcrição reversa e PCR devem ser feitas no mesmo tubo - one step RT-PCR; (iv) utilizando o método de extração de RNA SDS/acetato de potássio e one step RT-PCR, não há necessidade da inoculação dos viroides em cidra. De acordo com os mesmos autores, esse procedimento possibilita a deteç̧ão rotineira dos viroides que, em conjunto com outros métodos como sPAGE, pode ser utilizada para certificação. Para a amplificação via RT-PCR de viroides, na maioria dos casos, são utilizados iniciadores adjacentes, imediatamente opostos, normalmente desenhados para anelamento na CCR (região conservada entre viroides do mesmo gênero), que permitem a amplificação do genoma completo do viroide.

\section{Técnicas de Hibridização}

A técnica de hibridização dot-blot, em particular, permite que se analise um grande número de amostras de maneira fácil, rápida e a um custo relativamente baixo. Este método foi desenvolvido por Owens \& Diener (1981) para o diagnóstico de viroides, utilizando sondas marcadas com isótopos radioativos. Anos mais tarde, a técnica era largamente empregada para a deteç̧ão de ácidos nucleicos, sendo publicados, a partir de então, uma série de trabalhos para a detecção de vírus, viroides e outros patógenos por hibridização dot-blot (Pallás et al., 1998).

A hibridização de impressões de tecidos é um teste sensível e simples, utilizado para se detectar viroides em tecidos infectados (Palacio et al., 2000; Targon et al., 2001, 2005, 2006). O tecido fresco é cortado e a superfície é impressa em membranas de náilon carregadas positivamente. As amostras são fixadas e as membranas podem ser utilizadas imediatamente para hibridização ou guardadas. Também nesse teste, para melhor sensibilidade e reprodutibilidade, é preciso amplificar os viroides em cidra. Do mesmo modo que para dot-blot, com uma única hibridização usando uma mistura de sondas, amostras livres de viroides e amostras contendo viroides podem ser facilmente analisadas. Membranas contendo controles positivos e negativos podem ser facilmente comercializadas em forma de kits. Atualmente, é considerado o teste mais prático para ser utilizado rotineiramente. Sondas de cDNA 
específicas de CEVd e de viroides dos outros grupos foram desenvolvidas e usadas em dot-blot e hibrização de impressão de tecidos para a detecção específica dos diferentes viroides de citros (Gillings et al., 1988). A detecção do CEVd em amostras de campo por meio de dot-blot foi feita por Flores (1988). No entanto, métodos de detecção similares não se mostraram adequados para a detecção do HSVd em amostras de campo, devido ao seu baixo título em tecidos infectados (Levy et al., 1992). Deste modo, para melhor sensibilidade e reprodutibilidade do teste, é preciso bioamplificar os viroides por meio de inoculação em cidra e utilizar essa planta para extração de RNA.

Em situações onde não há necessidade de se identificar a espécie de viroide, pode ser feita uma única hibridização utilizando uma mistura de sondas (Targon et al., 2005). Cohen et al. (2006) construiram uma sonda múltipla (multiprobe) contendo clones de CEVd, HSVd, CBLVd e CVd-III. Essa sonda múltipla marcada com digoxigenina permitiu a detecção das respectivas espécies de viroides por Northern- e dot-blot. Neste caso, o viroide não é identificado, mas, de acordo com os autores, esse fato não deve ser considerado um problema, pois os programas de certificação descartam as plantas fontes de borbulhas que contenham qualquer espécie de viroide.

Northern-blot é outra técnica de hibridização que possibilita a detecção de moléculas de RNA após uma eletroforese. No caso específico de viroides, a eletroforese é realizada em géis de poliacrilamida (nativos ou desnaturantes), sendo os RNA em seguida transferidos a uma membrana de náilon para serem hibridizados com sondas de DNA ou RNA. A vantagem desse método em relação ao dot-blot é a possibilidade de se analisar os tamanhos das moléculas que hibridizam com a sonda, verificar a presença de monômeros e oligômeros lineares, além de reações não específicas. Na Figura 3C observa-se o resultado de um Northern-blot (após sPAGE) com sondas radioativas para detecção de CEVd em plantas de citros, onde é possível identificar as moléculas de RNA circulares e lineares.

A cada dia novos testes e estratégias são desenvolvidos para detecção de viroides (Murcia et al., 2009). A escolha do método de detecção vai depender da finalidade do trabalho, da disponibilidade de espaço e de recursos financeiros. Para os viroides de citros, a detecção é importante, principalmente, nos programas de certificação.
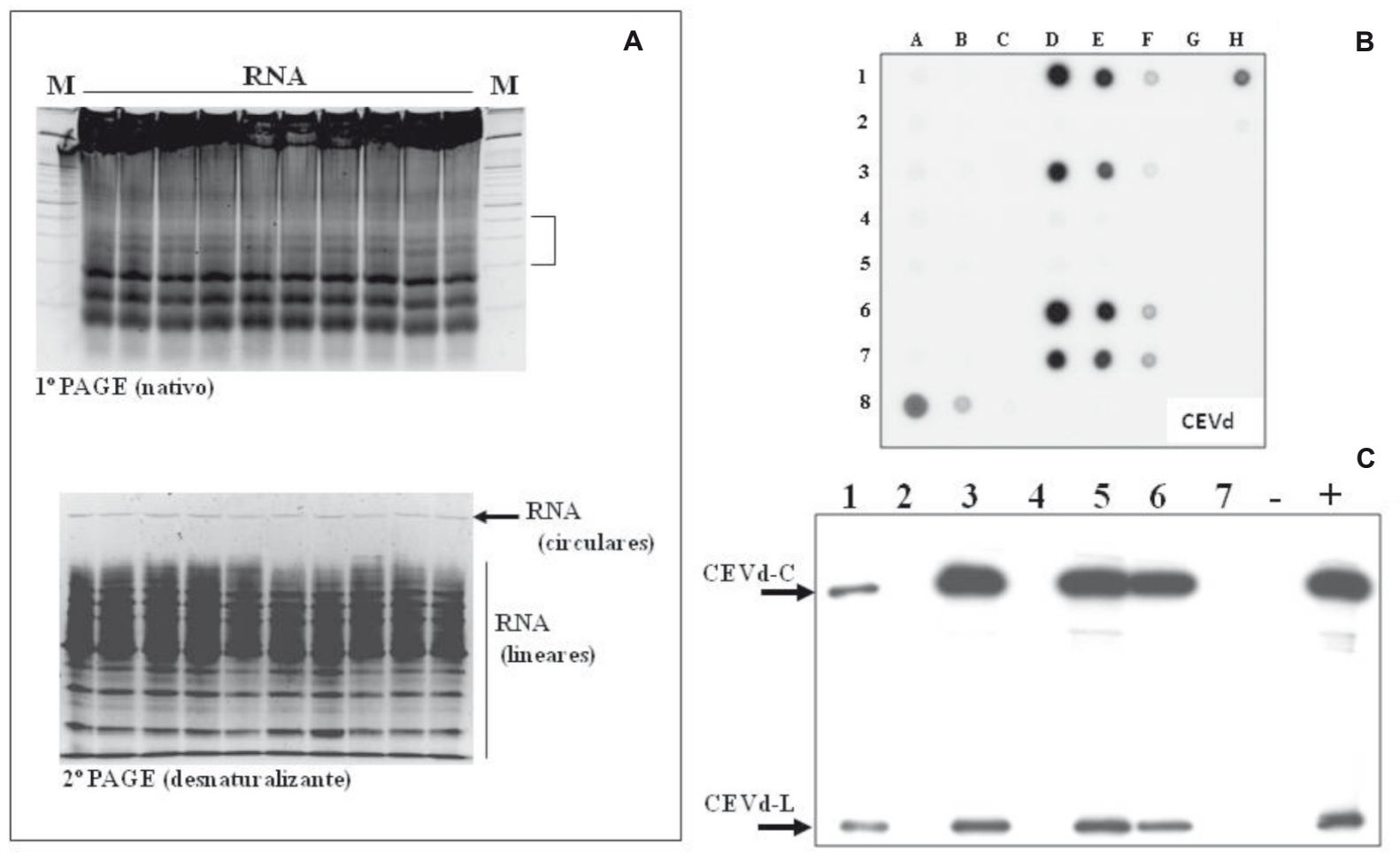

FIGURA 3 - Métodos moleculares para detecção de viroides; A. sPAGE de amostras de RNA total extraídos de plantas de cidra infectadas pelo Citrus viroid V (CVd-V). O colchete indica a região que foi cortada do primeiro gel (entre 200 e 400 $\mathrm{pb}$ ) e transferida para o segundo gel (desnaturalizante). Observa-se após a segunda PAGE a separação dos RNA circulares (viroides) dos lineares. M - marcador de tamanho de DNA 100 bp (Roche); B. Hibridização dot-blot, com sonda específica para a detecção de moléculas de polaridade positiva de CEVd, de amostras de RNA total extraídos de plantas de cidra infectadas com viroides; C. Detecção de RNA de polaridade positiva, após sPAGE, por Northern-blot com sonda específica para o $\mathrm{CEVd}$. CEVd-C corresponde às moléculas circulares e CEVd-L às lineares do CEVd. 
Nas condições do Estado de São Paulo, a indexação biológica, ou sua associação aos métodos moleculares são utilizadas há muitos anos com sucesso. A possibilidade de indexação in vitro com o uso de plântulas ou microestacas, apresenta-se como alternativa interessante para a diminuição de tempo e custos para o diganóstico.

\section{MATERIAL PROPAGATIVO LIVRE DE VIROIDES}

\section{Limpeza de viroides por meio de sementes}

Mesmo antes das primeiras descrições de ocorrência de viroides em citros, é provável que a recuperação de plantas de citros livres desses patógenos tenha ocorrido sistematicamente por meio da propagação das variedades de copa por meio de sementes, tanto nos centros de origem das espécies, quanto nas suas introduções e multiplicação em outras partes do globo. A partir do início do século 20, o emprego da enxertia em escala comercial trouxe, além das incontestáveis vantagens em relação à fidelidade e ausência de juvenilidade, a possibilidade de transmissão de patógenos sistêmicos, dentre eles os viroides, conforme evidenciado posteriormente pela ocorrência de pomares infectados com exocorte e xiloporose, notadamente nos países do mediterâneo, Brasil e Argentina, onde o uso de portaenxertos suscetíveis era mais comum (Wallace, 1978). Com o desenvolvimento de técnicas biológicas para detecção, estas doenças passaram progressivamente a incorporar os programas de registro e certificação de matrizes em todo o mundo, como o pioneiro instituído na Califórnia em 1937, inicialmente para solucionar o problema da sorose ao qual foi incluída a indexação para exocorte em 1965 (Calavan et al., 1978). Com o objetivo dirigido à obtenção de materiais livres de viroides e outros patógenos sistêmicos, o emprego de sementes também foi bastante útil nestes programas. Pela ausência de vascularização, a semente funciona como um filtro para os patógenos, e graças à ocorrência da poliembrionia é possível a obtenção de plantas geneticamente idênticas à planta mãe por meio de seleção de plântulas provenientes de embriões nucelares, derivados de células somáticas do nucelo (Frost \& Soost, 1968). O sucesso do emprego da embrionia nucelar no Brasil para a eliminação de exocorte e xiloporose, cuja presença nos pomares ficou evidente com o emprego do limoeiro 'Cravo' em substituição à laranja 'Azeda' (Moreira \& Salibe, 1965), possibilitou a implantação oficial, em 1969, do Programa de Registro de Matrizes do Estado de São Paulo (Greve et al., 1991), base para desenvolvimento nas próximas décadas da maior agroindústria citrícola mundial (Salibe, 1987).

\section{Quimioterapia e Termoterapia}

Não foram encontrados relatos sobre o uso de quimioterapia para eliminação de viroides em plantas de citros. Entretanto, pode-se esperar algum efeito deste tipo de tratamento, uma vez que Bells et al. (1986), citados por Barba et al. (2003), mostraram que amantadine, uma molécula ativa contra diversas viroses, foi eficiente na eliminação de CEVd de plantas de G. aurantiaca por aplicação foliar em concentrações superiores a $300 \mathrm{mg} . \mathrm{L}^{-1}$, ocorrendo fitotoxicidade a partir de $1600 \mathrm{mg} . \mathrm{L}^{-1}$.

A termoterapia, utilizada por séculos na eliminação de doenças e organismos de sementes e tecidos de plantas, é uma maneira efetiva e ecológica de erradicar patógenos de material propagativo. Para os citros, apresenta importante uso na eliminação de sorose A, sorose B, gomose-côncava, impietratura, cristacortis, infecção variegada, huanglongbing ("ex-greening"), tristeza, "tatterleaf" e "vein enation" (Roistacher, 1985). Relatado por Barba et al. (2003), buscando uma alternativa ao emprego da embrionia nucelar, o tratamento térmico foi a primeira estratégia empregada na tentativa de eliminação de viroides em material vegetal. Wallace (1978) relata que pesquisas pioneiras, realizadas na década de 1960 com ramos destacados ou plantas inteiras, indicaram que mesmo sendo possíveis tratamentos por períodos prolongados, como $35^{\circ} \mathrm{C}$ por dois anos ou a $38^{\circ} \mathrm{C}$ por 230 dias, a eliminação do víróide não era muito eficiente, o que está associado ao bom desenvolvimento deste tipo de patógenos em elevadas temperaturas. Conforme Roistacher (1977), trabalhos posteriores, realizados por diferentes grupos, confirmaram a inviabilidade de aplicação desta técnica para limpeza de viroides de citros. Mesmo não sendo efetiva na eliminação de viroides, é recomendável, entretanto, que a termoterapia seja adotada como estratégia adicional para garantir maior segurança nos trabalhos de limpeza clonal via microenxertia (ver detalhes mais adiante). Para isso, plantas inteiras podem ser mantidas em câmaras climáticas tipo "Fitotron" a $38^{\circ} \mathrm{C}$ com 16 horas de luz e $32^{\circ} \mathrm{C}$ com 8 horas de luz por período de 7 a 60 dias. Brotações emitidas nessas condições são retiradas para a obtenção dos ápices meristemáticos para a realização da microenxertia (Carvalho et al., 2002). A utilização de estacas separadas inoculadas em tubos de ensaio, em equipamentos menores e de menor custo de manutenção como as câmaras de germinação e crescimento tipo "B.O.D." (Biologic Oxygen Demand), pode proporcionar maior economia, além da praticidade na aplicação destes tratamentos (Carvalho et al., 2005). Segundo Navarro \& Juarez (2007), a manutenção de plantas desfolhadas em câmaras ou ramos destacados in vitro sob temperatura constante de $32^{\circ} \mathrm{C}$ é efetiva para termoterapia de citros, sendo estes procedimentos utilizados como rotina em apoio ao programa de saneamento e certificação de citros da Espanha.

\section{Microenxertia de ápices caulinares}

Devido à falta de uma conexão vascular entre células meristemáticas e pequenos primórdios foliares do resto da planta, aquelas se apresentam frequentemente livres de vírus e viroides, mesmo em plantas sistematicamente infectadas. Portanto, a recuperação de plantas livres de patógenos pode ser obtida pela regeneração in vitro de plantas de ápices meristemáticos excisados de plantas doentes. Este fato foi primeiramente demonstrado na eliminação de vírus em dália no inicio da década de 1950 e, desde então, tem sido 
utilizada para se eliminar numerosos patógenos de diversas espécies (Barba et al., 2003). Uma vez que o tratamento térmico não era efetivo na eliminação de viroides em citros, a cultura de meristemas seria, portanto, uma forma efetiva para a limpeza. Entretanto, para plantas lenhosas não é possível a recuperação do meristema in vitro. Assim, uma técnica alternativa para produzir plantas livres de exocorte foi desenvolvida por Murashige et al. (1972), constando da enxertia dos ápices meristemáticos sobre porta-enxertos desenvolvidos in vitro. Aperfeiçoada por Navarro et al. (1975), a microenxertia é atualmente utilizada em todo o mundo para a eliminação de patógenos sistêmicos de citros, sem os inconvenientes da juvenilidade da embrionia nucelar, que não permite também a recuperação de materiais monoembriônicos (Navarro \& Juárez, 2007). Todos os viroides de citros são facilmente eliminados utilizando um meristema composto do ápice meristemático mais três primórdios foliares medindo 0,1 a $0,2 \mathrm{~mm}$. Entretanto, como reportado em diferentes trabalhos, é muito difícil se obter plantas sadias com o uso de meristema maiores, entre 0,6 e $0,8 \mathrm{~mm}$. Por este motivo, há relatos de que viroides de citros podem também ser separados de infecções mistas por microenxertia (Barba et al., 2003).

Diferentes variedades de porta-enxertos podem ser utilizadas para a microenxertia, sendo na Espanha e no Brasil mais comum o uso do citrange 'Troyer' [Poncirus trifoliata (L.) Raf. x C. paradisi Macfad.] (Carvalho et al., 2005; Navarro \& Juarez, 2007). Para que fiquem estioladas e com o caule mais tenro, facilitando o corte, estas são germinadas no escuro em tubos de ensaio com meio de cultura MS (Murashige \& Skoog, 1962), solidificado com $1 \%$ de ágar e $\mathrm{pH}$ ajustado a 5,7. Os brotos, obtidos de plantas mantidas no campo, casa-de-vegetação ou câmaras de termoterapia, são manipulados assepticamente sob lupa estereoscópica em câmara de fluxo laminar, utilizando-se estiletes e bisturis cirúrgicos para a realização dos cortes e separação do ápice meristemático. A microenxertia é efetuada pela inoculação da porção apical de $0,2 \mathrm{~mm}$ do ápice caulinar, composta do meristema mais duas a três folhas, em uma incisão em forma de " $T$ " invertido na haste do microporta-enxerto estiolado, previamente podado na raiz e no topo. Uma variação da técnica, com a inserção do ápice meristemático em incisão de 0,3 a $0,4 \mathrm{~mm}$ realizada na lateral do caule do porta-enxerto, é proposta por $\mathrm{Su} \& \mathrm{Chu}$ (1984). Após a insersão, esta janela aberta a 2-3 mm do topo é coberta com tecido da mesma dimensão do retirado do mesmo porta-enxerto. O pegamento neste processo chega a $60 \%$, superior à média de $20 \%$ obtida com a enxertia em incisão em "T" invertido apical. Após a operação de microenxertia, o conjunto é colocado em tubos de ensaio em meio MS líquido e mantido em câmara de crescimento até a confirmação do pegamento e desenvolvimento satisfatório do broto. Em seguida, é transplantado diretamente para vasos, ou feita enxertia do conjunto obtido por garfagem lateral ou de topo em porta-enxerto estabelecido em vaso, com proteção de minicâmara úmida até a retirada do fitilho, conforme metodologia proposta por De Lange (1978) e adaptada por Paiva \& Carvalho (1993). Após aclimatação e desenvolvimento suficiente, as plantas recuperadas pela aplicação da termoterapia e microenxertia devem, novamente, ser indexadas para confirmação da eliminação dos viroides, utilizando-se as técnicas descritas nos tópicos anteriores. A aplicação desta metodologia no Laboratório de Biotecnologia do Centro APTA-Citros Sylvio Moreira, Instituto Agronômico de Campinas (IAC), tem proporcionado $100 \%$ de sucesso na limpeza dos viroides da exocorte e xiloporose, detectados, respectivamente em 19\% e 9\% dos clones velhos do Banco Ativo de Germoplasma de Citros da Unidade (Carvalho et al., 2003b, 2005).

$\mathrm{O}$ emprego da microenxertia de ápices caulinares é atualmente a técnica mais adequada para a limpeza de viroides, sem os inconvenientes da embrionia nucelar, com praticidade e eficiência também não alcançada por outros métodos como a termoterapia ou quimioterapia. Não obstante seu largo emprego em todo o mundo, incluindo o uso como ferramenta de apoio na recuperação de plantas obtidas por transformação genética e outras técnicas (Navarro \& Juarez, 2007), seu aprimoramento e o desenvolvimento de outras estratégias certamente serão objetivo de novas investigações. Como exemplo, pode-se citar a proposta de D’Onghia et al. (1997) de que, assim como para videira, a embriogênese somática possa ser considerada como uma técnica de potencial uso em programas de limpeza de citros. Atribuindo a perda dos agentes infecciosos durante a proliferação de calus, estes autores recuperaram plantas sadias de limão verdadeiro por meio da cultura de embriões somáticos obtidos da cultura de estilo de plantas infectadas com diferentes viroses, incluindo o viroide da exocorte. Finalmente, deve-se ressaltar a importância de medidas complementares após a obtenção de materiais sadios para viroides ou qualquer outro patógeno de citros, de maneira a desenvolver um programa eficiente de controle sanitário de material de propagação. Nas condições em que o vírus da tristeza dos citros é endêmico, como no Brasil, visando à proteção contra isolados fortes, após a limpeza clonal é necessário que plantas de variedades mais sensíveis ao vírus, como a laranja 'Pêra', sejam pré-imunizadas, empregando isolados fracos protetivos (Müller \& Costa, 1979). Após avaliação agronômica e confirmação da manutenção da pureza varietal, essa nova planta pode ser registrada como matriz para retirada de sementes ou borbulhas para utilização na formação de novas mudas. Para evitar a recontaminação por viroides, o manejo das plantas deve ser feito com o cuidado de desinfecção de ferramentas como canivetes e tesouras de poda, sendo a verificação realizada periodicamente por meio de testes de indexação. No Brasil, em que há ocorrência de doenças transmitidas por vetores, como afídeos transmissores de tristeza, cigarrinhas de clorose variegada dos citros, e psilídeos do huanglongbing, matrizes, borbulheiras e blocos de multiplicação e mudas em viveiros devem ser mantidas sob telado. 


\section{AGRADECIMENTOS}

Os autores agradecem ao Professor G.W. Müller por fornecer a foto de sintoma de xiloporose que ilustra a Figura 1; à Dra. L.M.L. Duarte pela leitura crítica do manuscrito e excelentes sugestões; ao Conselho Nacional de Desenvolvimento Científico e Tecnológico - CNPq (Proc. 474522/2007-5), pelo suporte financeiro.

\section{REFERÊNCIAS BIBLIOGRÁFICAS}

Ashulin L, Lachman O, Hadas R, Bar-Joseph M (1991) Nucleotide sequence of a new viroid species, citrus bent leaf viroid (CBLVd) isolated from grapefruit in Israel. Nucleic Acids Research 19:4767.

Astruc N, Marcos JF, Macquaire G, Candresse T, Pallás V (1996) Studies on the diagnosis of hop stunt viroid in fruit trees: identification of new hosts and application of a nucleic acid extraction procedure based on non-organic solvents. European Journal of Plant Pathology 102:837-846.

Barba M, Regazzino W, Navarro L (2003) Viroid Elimination by thermotherapy and tissue culture. In: Hadidi A, Flores R, Randles JW, Semancik JS (Eds.) Viroids. Collingwood. CSIRO Publishing. pp. 318-321.

Barbosa CJ (2004) Comportamiento de espécies de cítricos, híbridos y gêneros afines frente a la infección con viroides. Evaluación del impacto de la transmisión mecânica. Tesis (Doctoral en Ecosistemas Agroforestales) - Universidad Politécnica de Valencia.

Barbosa CJ, Duran-Vila N (2005) Comportamento do limão 'Cravo' à inoculação com diferentes espécies de viroides dos citros. Embrapa Mandioca e Fruticultura Tropical. Boletim de Pesquisa, 37.

Barbosa CJ, Pina JA, Pérez-Panadés J, Bernad L, Serra P, Navarro L, Duran-Vila N (2005a) Mechanical transmission of citrus viroids. Plant Disease 89:749-754.

Barbosa CJ, Serra P, Pina JÁ, Navarro L, Daròs JÁ, Flores R, DuranVila N (2005b) Identification and preliminary characterization of a viroid-like RNA in Atalantia citroides. In: Hilf ME, DuranVila N, Rocha-Peña MA (Eds.) Proceedings, XVI International Conference Citrus Virologists. Riverside CA. pp. 264-271.

Bar-Joseph M (2003) Natural history of viroids - horticultural aspects. In: Hadidi A, Flores R, Randles JW, Semancik JS (Eds.) Viroids. Collingwood. CSIRO Publishing. pp. 246-251.

Bellamy AR, Ralph RK (1968) Recovery and purifications of nucleic acids by means of cetyltrimethilammonium bromide. Methods Enzymology 2B:156-169.

Benton RJ, Bowman FT, Fraser L, Kebby RG (1949) Selection of citrus budwood to control scaly butt in trifoliata rootstock. Agr. Gaz. N.S. Wales 60: 31-34.

Bernad L, Duran-Vila N (2006) A novel RT-PCR approach for detection and characterization of citrus viroids. Molecular and Cellular Probes 20:105-113.

Bielsa AP (1999) La exocortis y la cachexia de los citricos: mejora de los métodos de detección y caracterización Tese de Doutorado. Universidad Politécnica de Valencia.
Calavan EC, Frolich EF, Carpenter JB, Roistacher CN, Christiansen DW (1964) Rapid indexing for exocortis of citrus. Phytopathology 54:1359-1362.

Calavan EC, Mather SM, McEachern EH (1978) Registration, certification, and indexing of citrus tress. In: Reuther, W, Calavan, EC, Carnan CE (Eds.) The Citrus Industry. Riverside CA. University of California. pp. 185-222.

Calavan EC, Weathers LG (1961) Evidence for strain differences and stunting with exocortis virus. Proceedings, Conference of the International Organization of Citrus Virologists 2:26-33.

Cañizares MC, Marcos JF, Pallás V (1998) Studies on the incidence of hop stunt vitoid in apricot trees (Prunus americana) by using an easy and short extraction method to analyse a large number of samples. Acta Horticulturae 472:581-585.

Carbonell A, Martínez de Alba, AE, Flores R, Gago S (2008) Double-stranded interferes in a sequence-specific manner with the infection of representative members of the two viroid families. Virology 371:44-53.

Carvalho AS, Santos FA, Machado, MA (2002) Eliminação de vírus do complexo sorose de citros por microenxertia associada à termoterapia. Fitopatologia Brasileira 27:306-308.

Carvalho SA, Graf, CCD, Violante AR (2005) Produção de Material Básico e Propagação. In: Mattos Junior D, De-Negri D, Pio RM, Pompeu Junior J (Eds.) Citros. Campinas SP. Instituto Agronômico-Fundag, Cap. 10. pp. 279-316.

Carvalho SA, Machado MA, Müller GW (2003a) Avaliação de indicadoras e porta-enxertos na indexação biológica do viroide da xiloporose em citros. Laranja 24:145-155.

Carvalho SA, Machado MA, Müller GW (2003b) Strategies under Development by the Centro de Citricultura Sylvio Moreira - IAC to Supply Basic Material for Production of healthy citrus nursery trees in São Paulo State, Brazil. Proceedings, IX International Congress of Citriculture, Orlando FL, 2000. International Society of Citriculture. pp. 998-1000.

Chaffai M, Serra P, Gandía M, Hernández C, Duran-Vila N (2007) Molecular characterization of CEVd strains that induce different phenotypes in Gynura aurantiaca: structure-pathogenicity relationships. Archives of Virology 152:1283-1294.

Childs JFL (1950) The cachexia disease of Orlando tangelo. Plant Disease Reporter 34:295-298.

Cohen O, Batuman O, Stanbekova G, Sano T, Mawassi M, BarJoseph M (2006) Construction of a multiprobe for the simultaneous detection of viroids infecting citrus trees. Virus Genes 33:287-92.

De Lange JH (1978) Shoot-tip grafting - a modified procedure. Citrus and Subtropical Fruit Journal 539:13-15.

Diener TO (1971) Potato spindle tuber 'virus' IV. A replicating, low molecular weight RNA. Virology 45:411-428.

Diener TO (1991) The frontier of life: the viroids and viroid-like satellite RNAs. In: Maramorosch K (Ed.) Viroids and Satellites: Molecular Parasites at the Frontier of Life. London. CRC Press. pp. 1-20.

Ding B (2009) The biology of viroid-host interactions. Annual Review of Phytopathology 47:105-131.

Ding B, Wang Y (2009) Viroids: uniquely simple and tractable models to elucidate regulation and cell-to-cell trafficking of RNA. DNA and Cell Biology 28:1-6. 
D’Onghia AM F, Pasquale F, Carimi F, Savino V, Crescimanno FG (1997) Somatic Embryogenesis from Style Culture as a possible means for virus elimination in Citrus Journal of Phytopathology 145:77-79.

Duran-Vila N (1989a) Enfermedades de los citricos producidas por viroides: la exocortiis y la cachexia-xyloporosis. Fruticultura Profesional 25: 57-64 (Especial Cítricos)

Duran-Vila N (1989b) Enfermedades producidas por viroides: la exocortis de los cítricos. Phytoma España 7:19-25.

Duran-Vila N (2000) Enfermedades producidas por viroides y agentes similares. In: Duran-Vila N, Moreno P (Eds.) Enfermedades de los citricos. Valencia. Sociedade Espanhola de Fitopatologia, Mundi-Prensa. pp. 87-92.

Duran-Vila N, Flores R, Semancik JS (1986) Characterization of viroid-like RNAs associated with the citrus exocortis syndrome. Virology 150:75-84.

Duran-Vila N, Pina JA, Ballester JF, Juarez J, Roistacher CN, Rivera-Bustamante R, Semancik JS (1988a) The citrus exocortis disease: a complex of viroid RNAs. Proceedings, Conference of the International Organization of Citrus Virologists 10:152164.

Duran-Vila N, Roistacher CN, Rivera-Bustamante R, Semancik JS (1988b) A definition of citrus viroid groups and their relationship to the exocortis disease. Journal of General Virology 69:3069-3080.

Duran-Vila N, Semancik JS (1990) Variations in the "cross proteccion" effect between two strains of citrus exocortis viroids. Annals of Applied Biology 117:367-377.

Duran-Vila N, Pina JA, Navarro L (1993) Improved indexing of citrus viroids. In: Moreno P, Graça JV, Timmer LW (Eds.). Proceedings, XII Conference of the International Organization of Citrus Virologists. Riverside CA. pp. 202-211.

Duran-Vila N, Semancik JS (2003) Citrus viroids. In: Hadidi A, Flores R, Randles JW, Semancik JS (Eds.) Viroids. Collingwood. CSIRO Publishing. pp. 178-194.

Eiras M, Daròs JA, Flores R, Kitajima EW (2006) Viroides e virusóides: relíquias do mundo de RNA. Fitopatologia Brasileira 31:229-246.

Fadda Z, Daròs JA, Flores R, Duran-Vila N (2003) Identification in eggplant of a variant of citrus exocortis viroid (CEVd) with a 96 nucleotide duplication in the right terminal region of the rod-like secondary structure. Virus Research 97: 145-149.

Fagoaga C, Duran-Vila N (1996) Naturally occurring variants of citrus exocortis viroid in vegetable crops. Plant Pathology 45:45-53.

Fawcet HS, Klotz LJ (1948) Exocortis on trifoliate orange. Citrus Leaves 28:8.

Flores, R (1988) Detection of citrus exocortis viroid in natural and experimental hosts by biochemical methods. In: Proceedings, X Conference of the International Organization of Citrus Virologists. Riverside CA. pp. 192-196.

Flores R, Duran-Vila N (1996) Viroides. Phytoma España 1:149183.

Flores R, Hernandez C, Martínez de Alba AE, Daròs JA, Di Serio F (2005a) Viroids and viroid-host interactions. Annual Review of Phytopathology 43:117-139.
Flores R, Randles JW, Owens RA, Bar-Joseph M, Diener TO (2005b) Viroidae. In: Fauquet CM, Mayo MA, Maniloff J, Desselberger U, Ball AL (Eds.) Virus taxonomy: eighth report of the International Committee on Taxonomy of Viruses. London. Elsevier Academic Press. pp. 1145-1159.

Flores R, Owens RA (2008) Viroids. In: Mahy BWJ, Van Regenmortel MHV (Eds.) Encyclopedia of Virology. Oxford. Elsevier. pp. 332-342.

Foissac X, Duran-Vila N (2000) Characterization of two citrus apscaviroids isolated in Spain. Archives of Virology 145:19751983.

Fraser LR, Levitt EC (1959) Recent advances in the study of exocortis (scally butt) in Australia. In: Wallace JM (Ed.) Citrus Virus Diseases 129-133. University of California, Div. Agr. Science.

Frost HB, Soost RK (1968) Seed reprodution: development of gametes and embryos. In: Reuther W, Batchelor LD, Webber HJ (Eds) The Citrus Industry. Riverside CA. University of California. pp. 290-324.

Gandía M, Palacio A, Duran-Vila N (2000) Variability of citrus exocortis viroid (CEVd). Proceedings, XIV Conference of the International Organization of Citrus Virologists 14:265-272.

Gandía M, Duran-Vila N (2002) Effect of sequence variation on the biological properties of citrus exocortis viroid (CEVd). Proceedings, XV Conference of the International Organization of Citrus Virologists 15:213-218.

Gandía M, Duran-Vila N (2004) Variability of the progeny of a sequence variant of Citrus bent leaf viroid (CBLVd). Archives of Virology 149:407-416.

Gandía M, Rubio L, Palacio A, Duran-Vila N (2005) Genetic variation and population structure of an isolate of Citrus exocortis viroid $(\mathrm{CEVd})$ and of the progenies of two infectious sequence variants. Archives of Virology 150:1945-1957.

Gandía M, Bernard L, Rubio L, Duran-Vila N (2007) Host effect on the molecular and biological properties of a Citrus exocortis viroid (CEVd) isolate from Vicia faba. Phytopathology 97:1004-1010.

García-Arenal F, Pallás V, Flores R (1987) The sequence of a viroid from grapevine closely related to severe isolates of citrus exocortis viroid. Nucleic Acids Research 15:4203-4210.

Gillings MR, Broadbent P, Gollnow BI (1988) Biochemical indexing for citrus exocortis viroid. In: Proceedings, $\mathrm{X}$ Conference of the International Organization of Citrus Virologists. Valencia 1986. Riverside CA. pp. 178-187.

Gillings MR, Broadbent P, Gollow BI (1991) Viroids in Australian Citrus: relationship to exocortis, cachexia and citrus dwarfing. Australian Journal Plant Physiology 18:559-570.

Gomez G, Martínez G, Pallás V (2009) Interplay between viroidinduced pathogenesis and RNA silencing pathways. Trends in Plant Science. No prelo.

Greve A, Prates HS, Müller GW (1991) Produção de borbulhas certificadas de citros no Estado de São Paulo. In: Rodriguez O, Viégas F, Pompeu-Júnior J, Amaro AA (Eds.) Citricultura brasileira. Campinas SP. Fundação Cargill. pp. 302-317.

Gross HJ, Krupp G, Domdey H, Raba M, Jank P, Lossow C, Alberty H, Ramm K, Sänger HL (1982) Nucleotide sequence and secondary structure of citrus exocortis and chrysanthemum stunt viroid. European Journal of Biochemistry 121:249-257. 
Gumpf DJ, Navarro L (2003) Availability of viroid-tested propagation materials. In: Hadidi A, Flores R, Randles JW, Semancik JS (Eds.). Viroids. Collingwood. CSIRO Publishing. pp. 312-317.

Hadas R, Bar-Joseph M, Semancik JS (1989) Segregation of a viroid complex from a graft-transmissible dwarfing agent source for grapefruit trees. Annals Applied Biology 115:515520 .

Hadas R, Bar-Joseph M (1991) Variation in tree size and rootstock scalling of grapefruit inoculateed with a complex of citrus viroids. Proceedings, XI Conference of the International Organization of Citrus Virologists. Riverside CA. pp. 240243.

Hadas R, Ashulin L, Bar-Joseph M (1992) Transmission of a citrus viroid to avocado by heterologous grafting. Plant Disease 76:357-359.

Hadidi A, Flores R, Randles JW, Semancik JS (2003). Viroids. Collingwood. CSIRO Publishing.

Hataya T, Nakahara K, Ohara T, Ieki H, Kano T (1998) Citrus viroid Ia is a derivative of citrus bent leaf viroid (CVd-Ib) by partial sequence duplications in the terminal region. Archives of Virology 143:971-980.

Ito T, Ieki H, Ozaki K (2000) A population of variants of a viroid closely related to citrus viroid-I in citrus plants. Archives of Virology 145:2105-2114.

Ito T, Ieki H, Ozaki K, Ito T (2001) Characterization of a new citrus viroid species tentatively termed citrus viroid OS. Archives of Virology 146:975-982.

Ito T, Ieki H, Ozaki K, Iwanami T, Nakahara K, Hataya T, Ito T, Isaka M, Kano T (2002) Multiple citrus viroids in citrus from Japan and their ability to produce exocortis-like symptoms in citron. Phytopathology 92:542-547.

Kapari-Isaia T, Kyriakou A, Papayiannis L, Tsaltas DS, Gregoriou I, Psaltis I (2008) Rapid in vitro microindexing of viroids in citrus. Plant Pathology 57:348-353.

Keese P, Symons RH (1985) Domains in viroids: evidence of intermolecular RNA rearrangements and their contribution to viroid evolution. Proceedings of the National Academy of Sciences of the USA 82:4582.

Levy L, Hadidi A (1993) Direct nucleotide sequencing of PCR-amplified DNAs of closely-related citrus viroids IIa and IIb (cachexia). In: Moreno P, Graça JV, Timmer LW (Eds.). Proceedings, XII Conference of the International Organization of Citrus Virologists. Riverside CA. pp. 180186.

Levy L, Hadidi A, Garnsey S (1992) Reverse-transcription Polymerase chain reaction assays for the rapid detection of citrus viroids using multiplex primer sets. Proceedings International Society Citriculture 7:800-803.

Mattos Junior D, De Negri JD, Pio RM, Pompeu Junior J (Eds.) (2005). Citros. $1^{\mathrm{a}}$ ed. Campinas SP. Instituto Agronômico, Fapesp, Vol. 1.

Mischra MD, Hammond RW, Owens RA, Smith DR, Diener TO (1991) Indian bunchy top disease of tomato plants is caused by a distinct strain of citrus exocortis viroid. Journal General Virology 72:1781-1785.
Moreira S (1954) Exocortis: Outra moléstia de vírus nos laranjais paulistas. O Agronômico 6:10-12.

Moreira S (1955) Sintomas de 'exocortis' em limoeiro cravo. Bragantia 14:19-21.

Moreira S (1959) Rangpur lime disease and its relationship to exocortis. In: Wallace JM (Ed.) Citrus virus diseases. University of California Div. Agr. Sci.: Berkeley CA. pp. 135-140.

Moreira S, Salibe AA (1965) Nucellar lines in the State of São Paulo, Brazil. Proceedings, III Conference of International Organization of Citrus Virologists, Campinas 1963. IOCV, Gainesville FL. pp. 309-313.

Müller GW, Costa AS (1979) Tristeza control in Brazil by preimunization with mild strains. Proccedings, International Citrus Congress, Orlando FL. International Society of Citricultura. pp. 868-872.

Müller GW, Targon MLPN, Carvalho SA, Souza AA, Rodrigues JCV (2005) Doenças de citros causadas por vírus e viroides. In: Mattos Junior D, De Negri JD, Pio RM, Pompeu Junior J (Eds.) Citros. Campinas SP. Instituto Agronômico-Fundag. pp. 569-596.

Murashige T, Skoog F (1962) A revised medium for rapid growth and biossays with tobacco tissue cultures. Physiologia Plantarum $15: 473-479$.

Murashige T, Bitters WP, Rangan TS, Nauer EM, Roistacher CN, Holliday PBO (1972) A technique of shoot apex grafting and its utilization towards recovering virus-free citrus clones. HortScience 7:118-119.

Murcia N, Serra P, Olmos A, Duran-Vila N (2009) A novel hybridization approach for detection of citrus viroids. Molecular and Cellular Probes 23:95-102.

Navarro L, Roistacher CN, Murashige T (1975) Improvement of shoot-tip graffting in vitro for virus-free citrus. Journal of the American Society for Horticultural Science 100:471-479.

Navarro L, Juárez J (2007) Shoot-tip grafting in vitro: impact in the citrus Industry and research applications. In: Khan I (Ed.) Citrus: Genetics, Breeding and Biotechnology, Wallingford. CAB International. Cap. 17. pp. 353-364.

Ohno T, Takamatsu N, Meshi T, Okada Y (1983) Hop stunt viroid: molecular cloning and nucleotide sequence of the complete cDNA copy. Nucleic Acids Research 11:61586197.

Olson EO (1968) Review of recent research on exocortis disease. Proceedings, Conference of the International Organization of Citrus Virologists 4:92-96.

Önelge N, Kersting U, Guang Y, Bar-Joseph M, Bozan O (2000) Nucleotide sequence of citrus viroids CVd-IIIa and CVd-IV obtained from dwarfed Meyer trees grafted on sour orange. Journal of Plant Disease and Protection 107:387-391.

Owens RA, Diener TO (1981) Sensitive and rapid diagnosis of potato spindle tuber viroid disease by nucleic acid hybridization. Science 213:670-672.

Owens RA, Candresse T, Diener TO (1990) Construction of novel viroid chimeras containing portions of tomato apical stunt and citrus exocortis viroids. Virology 175:238-246.

Owens RA, Thompson SM, Feldstein PA, Garnsey SM (1999) Effects of natural sequence variation on symptom induction by citrus viroid III. Annals of Applied Biology 134:73-80. 
Owens RA, Yang G, Gundersen-Rindal D, Hammond RW, Candresse T, Bar-Joseph M (2000) Both point mutations and RNA recombination contribute to the sequence diversity of citrus viroid III. Virus Genes 20:243-252.

Paiva LV, Carvalho SA (1993) Alternativa para promoção de crescimento in vivo de microenxertos de citros. Pesquisa Agropecuária Brasileira 28:1085-1099.

Palacio A, Duran-Vila N (1999) Single-strand conformation polymorphism (SSCP) analysis as a tool for viroid characterization. Journal of Virological Methods 77:27-36.

Palacio A, Foissac X, Duran-Vila N (2000) Indexing of citrus viroids by imprint hybridization. European Journal of Plant Pathology 105: 897-903.

Palacio-Bielsa A, Romero-Durbán J, Duran-Vila N (2004) Characterization of citrus HSVd isolates. Archives of Virology 149:537-552.

Pallás V, Gómez G, Duran-Vila N (2003) Viroids in Europe. In: Hadidi A, Flores R, Randles JW, Semancik JS (Eds.). Viroids. Collingwood. CSIRO Publishing. pp. 268-274.

Pallás V, Más P, Sánchez-Navarro JA (1998) Detection of plant RNA viruses by non-isotopic dot blot hybridization. In: Foster G, Taylor S (Eds.) Plant Virus Protocols: from virus isolation to transgenic resistance. Totowa. Humana Press. pp. 461-468.

Pérez R, Gonzalez A, Rello L, Marrero A (1992) Clemelin 1120, a new indicator plant for citrus cachexia. In: International Society of Citriculture, 7. Acireale. Proceedings... Acireale: ISC 2: 786-787.

Pina JA, Duran-Vila N, Navarro L (1991) Interference of citrus viroids with cachexia symptoms on Parson's Special mandarin. Proceedings, Conference of the International Organization of Citrus Virologists 11:206-208.

Puchta H, Ramm K, Luckinger R, Hadas R, Bar-Joseph M, Sänger HL (1991) Primary and secondary structure of citrus viroid IV (CVd-IV), a new chimeric viroid present in dwarfed grapefruit in Israel. Nucleic Acids Research 19:6640.

Rakowski, AG, Szychowski JA, Avena ZS, Semancik JS (1994) Nucleotide sequence and structural features of the Group III citrus viroids. Journal General Virology 75:3581-3584.

Reanwarakorn K, Semancik JS (1998) Regulation of pathogenicity in hop stunt viroid related group II citrus viroids. Journal General Virology 79:3163-3171.

Reanwarakorn K, Semancik JS (1999a) Correlation of hop stunt viroid variants to cachexia and xyloporosis diseases of citrus. Phytopathology 89:568-574.

Reanwarakorn K, Semancik JS (1999b) Discrimination of cachexia disease agents among of hop stunt viroid. Annals of Applied Biology 135:481-487.

Reichert I, Perlberger P (1934) Xyloporosis, the new citrus disease. Agr. Exp. Sta. Rehovoth, Palestine Bulletin 12:44.

Rodrigues MIS, Barbosa CJ, Santos Filho HP, Vilarinhos AD, Meissner Filho PE (1999) Caracterização biológica e molecular de viroides associados a exocorte dos citros. Fitopatologia Brasileira 24:528-533.

Roistacher CN (1977) Elimination of citrus pathogens in propagative budwood I. Budwood selection, indexing and thermotherapy. Proceedings, II Citrus International Congress. Riverside CA, 1997. International Society of Citriculture Vol. 3 University of California, Riverside, pp. 965-972.

Roistacher CN (1985) A historical review of the major grafttransmissible diseases of citrus. Riverside CA. FAO/Regional Office for the Near East.

Roistacher CN (1991) Graft-transmissible diseases of citrus - handbook for detection and diagnosis. International Organization of Citrus Virologists and Food and Agriculture Organization of the United Nations.

Roistacher CN, Calavan EC, Blue RL, Navarro L, Gonzales R (1977) A new more sensitive citron indicator for the detection of mild isolates of citrus exocortis viroid (CEV). Plant Disease Reporter 61:135-139.

Roistacher CN, Bash JA, Semancik JS (1993) Distinct disease symptoms in Poncirus trifoliate induced by three citrus viroids from three specific groups. In: Moreno P, Graça JV, Timmer LW (Eds.) Proceedings, Conference of the International Organization of Citrus Virologists. Riverside CA. pp. 173-179.

Rossetti V (1961) Testing for exocortis. Proceedings, Conference of the International Organization of Citrus Virologists 2:43-49.

Salibe AA (1961) Contribuição ao estudo da doença exocorte dos citros. Tese de Doutorado. ESALQ, Universidade de São Paulo. Piracicaba SP.

Salibe AA (1987) Clones nucelares de citros no Estado de São Paulo. Laranja 8:443-66.

Salibe AA, Moreira S (1965) Tahiti lime bark disease is caused by exocortis virus. Proceedings, Conference of the International Organization of Citrus Virologists 3:143-147.

Sambrook J, Russel DW (2001) Molecular cloning: a laboratory manual. Third Edition, Cold Spring Harbor Laroratory Press NY.

Sänger HL, Ramm K, Domdey H, Gross HJ, Henco K, Riesner D (1979) Conversion of circular viroid molecules to linear strands. FEBS Letters 99:117-122.

Sano T, Hataya T, Shikata E (1988) Complete nucleotide sequence of a viroid isolate from Etrog citron, a new member of hop stunt viroid group. Nucleic Acids Research 16:347.

Sano T, Candresse T, Hammond RW, Diener TO, Owens RA (1992) Identification of multiple structural domains regulating viroid pathogenicity. Proceedings of the National Academy of Sciences of the USA 89:10104-10108.

Sano T, Ishiguro A (1998) Viability and pathogenicity of intersubgroup viroid chimeras suggest possible involvement of the terminal right region in replication. Virology 240:238-244.

Schlemmer A, Roistacher CN, Semancik JS (1985) A unique, infectious RNA associated with citron showing symptoms typical of citurs exocortis disease. Phytopathology 75:946949.

Semancik JS (1986) Separation of viroid RNAs by cellulose chromatography indicating conformational distinction. Virology 155:39-45.

Semancik JS (1991) Viroid purification and characterization. In: Roistacher CN (Ed.) Graft-Transmissible Diseases of Citrus: Handbook for detection and Diagnosis. IOCV-FAO, Rome, pp. 233-241. 
Semancik JS, Weathers LG (1972a) Exocortis disease: Evidence for a new species of "infectious" low molecular weight RNA in plants. Nature New Biology 237:242-244.

Semancik JS, Weathers LG (1972b) Exocortis virus: An infectious free-nucleic acid plant virus with unusual properties. Virology 46:456-466.

Semancik JS, Morris TJ, Weathers LG, Rordorf GF, Kearns DR (1975) Physical properties of a minimal infectious RNA (viroid) associated with the exocortis disease. Virology 63:160-167.

Semancik JS, Roistacher CN, Rivera-Bustamente R, DuranVila N (1988) Citrus cachexia viroid, a new disease of citrus: relationship to viroids of the exocortis disease complex. Journal General Virology 69:3059-3068.

Semancik JS, Duran-Vila N (1990) The grouping of viroids: additional physical and biological determinants and relationchips with diseases of citrus. Proceedings, Conference of the International Organization of Citrus Virologists 11:178-188.

Semancik JS, Duran-Vila N (1991) The grouping of citrus viroids: Additional physical and biological determinantes and relationship with disease of citrus. In: Brlansky RH, Lee RF, Timmer LW (Eds.) Proceedings, XI Conference International Organization Citrus Virologists. Riverside CA. pp. 178-188.

Semancik JS, Szychowski JA, Rakowski AG, Symons RH (1993) Isolates of citrus exocortis viroid recovered by host and tissue selection. Journal General Virology 74:2427-2436.

Semancik JS, Rakowski AG, Bash JA, Gumpf DJ (1997) Application of selected viroids for dwarfing and enhancement of production of "Valencia" orange. Journal Horticultural Science 72:563-570.

Semancik JS, Vidalakis G (2005) The question of Citrus viroid IV as a Cocadviroid. Archives of Virology 150:1059-1067.

Serra P, Barbosa CJ, Daròs JA, Flores R, Duran-Vila N (2008a) Citrus viroid $V$ : molecular characterization and synergistic interactions with other members of the genus Apscaviroid. Virology 370:101-112.

Serra P, Eiras M, Bani Hashemian SM, Murcia N, Daròs JA, Flores R, Kitajima EW, Duran-Vila N (2008b) Citrus viroid $\mathrm{V}$ : occurrence, host range, diagnosis and identification of new variants. Phytopathology 98:1199-1204.

Serra P, Gago S, Duran-Vila, N (2008c) A single nucleotide change in Hop stunt viroid modulates citrus cachexia symptoms. Virus Research 138:130-134.

Silva SR (2007) Caracterização fitossanitária e seleção de limeiras ácidas 'Tahiti' clone Quebra-galho candidatas a matrizes. Tese de Doutorado, Universidade Estadual Paulista, Jaboticabal SP.

Singh RP (1991) Return-polyacrilamide gel eletrophoresis for the detection of viroids. In: Maramorosch K (Ed.) Viroids and satellites: molecular parasites at the frontier of life. Boca Raton FL. CRC Press. pp. 89-107.

Singh RP, Ready KFM, Nie X (2003) Biology. In: Hadidi A, Flores R, Randles JW, Semancik JS (Eds.). Viroids. Collingwood. CSIRO Publishing, pp. 30-48.

Skoric D, Conerly M, Szychowski JA, Semancik JS (2001) CEVd-induced symptom modification as a response to a hostspecific temperature-sensitive reaction. Virology 280:115-123.
Stasys RA, Dry IB, Rezaian MA (1995) The termini of as new citrus viroid contain duplications of a central conserved regions from two viroid groups. FEBS Letters 358:182-184.

Su HJ, Chu JY (1984) Modified technique of citrus shoottip grafting and rapid propagation method to obtain citrus budwoods free of citrus viruses and likubin organism. In: Proceedings, V. International Citrus Congrees. São Paulo SP. International Society of Citriculture, Vol. 2. pp. 332334.

Szychowski JA, Vidalakis G, Semancik JS (2005) Host-directed processing of Citrus exocortis viroid. Journal of General Virology 86:473-477.

Targon MLPN, Machado MA, Carvalho AS, Muller GW, Stuchi ES (2001) Diagnóstico molecular na detecção de viroides em citros. Laranja 22:243-257.

Targon MLPN, Carvalho AS, Stuchi ES, Souza JM, Müller GW, Borges KM, Machado MA (2005) Hybridization techniques for indexing of citrus viroids in São Paulo State, Brazil. Laranja 26:25-38.

Targon MLPN, Carvalho SA, Medina CL, Muller GW, Stuchi ES, Borges KM, Machado MA (2006) Identificação de viroides ocorrendo em pomares de lima ácida tahiti quebra-galho em Holambra (SP). Laranja 27:1-11.

Tsagris EM, Martinez de Alba AE, Gozmanova M, Kalantidis K (2008) Viroids. Cellular Microbiology 10:2168-2179.

Vernière C, Botella L, Dubois A, Chabrier C, Duran-Vila N (2002) Properties of Citrus Viroids: Symptoms Expression na Dwarfing. Proceedings, Conference of the International Organization of Citrus Virologists 15:240-248.

Vernière C, Perrier X, Dubois C, Dubois A, Botella L, Chabrier C, Bové JM, Duran-Vila, N (2004). Citrus viroids: symptom expression and effect on vegetative growth and yield of clementine trees grafted on trifoliate orange. Plant Disease 88:1189-1197.

Vernière C, Perrier X, Dubois C, Dubois A, Botella L, Chabrier C, Bové JM, Duran-Vila, N (2006) Interactions between citrus viroids affect symptom expression and field performance of clementine trees grafted on trifoliate orange. Phytopathology 93:356-368.

Vidalakis G, Gumpf DJ, Semancik JS (2004) Finger imprint of Poncirus trifoliata: a specific interaction of a viroid, a host, and irrigation. Plant Disease 88:709-713.

Visvader JE, Gould AR, Bruening GE, Symons RH (1982) Citrus exocortis viroid: nucleotide sequence and secondary structure of an Australian isolate. FEBS Letters 137:288292.

Visvader JE, Symons RH (1985) Eleven new sequence variants of citrus exocortis viroid and the correlation of sequence with pathogenicity. Nucleic Acids Research 13:2907-2920.

Visvader JE, Symons RH (1986) Replication of in vitro constructed viroid mutants: location of the pathogenicitymodulating domain of citrus exocortis viroid. EMBO Journal 5:2051-2055.

Wallace JM (1978) Virus and viruslike diseases. In: Roeuther W, Calavan EC, Carman GE (Eds.) The Citrus Industry. Riverside CA. University of California. Vol.4, Cap.2. pp. 67-184. 
Wheathers LG, Greer Jr. FC (1972) Gynura as a host for exocortis virus of citrus. Proceedings, V Conference of the International Organization of Citrus Virologists 5:95-98. Gainsville FL. University of Florida Press.
Yang X, Hadidi A, Garnsey S (1992) Enzymatic cDNA amplificarion of citrus exocortis and cachexia viroids from infected citrus hosts. Phytopathology 82:279-285.

Zuker M (1989) On finding all suboptimal foldings of an RNA molecule. Science 244:48-52.

TPP 9065 - Recebido 8 Maio 2009 - Aceito 14 Outubro 2009 Editores de Seção: F. Murilo Zerbini e Alice K. Inoue Nagata 